\title{
1 Tree crowns as meeting points of diversity generating 2mechanisms - a test with epiphytic lichens in a temperate forest
}

3Patzak R. ${ }^{1}$, Richter R. ${ }^{1,2,3}$, Engelmann R.A. ${ }^{1,2}$, Wirth C. ${ }^{1,2,4}$

4

$5^{1}$ Institute for Special Botany and Functional Biodiversity, University of Leipzig, 04103 Leipzig,

6Germany ${ }^{2}$ German Centre for Integrative Biodiversity Research (iDiv) Halle-Jena-Leipzig, 704103 Leipzig, Germany

$8^{3}$ Geoinformatics and Remote Sensing, Institute for Geography, Leipzig University, 04103

9Leipzig, Germany,

$10^{4}$ Max-Planck Institute for Biogeochemistry, 07745 Jena, Germany

11 


\section{Introduction}

13Forest canopies are known as hotspots of biological diversity (Ozanne et al. 2003, Nakamura et 14al. 2017). Approximately 28.600 vascular plant species inhabit tree crowns as epiphytes, which 15comprises about $10 \%$ of the total vascular flora (Nadkarni 1994). Extrapolations based on host 16specificity of arthropods with respect to tree species, resulted in a total number of 6.1 million 17terrestrial arthropod species harbored in the tropics (Hamilton et al. 2010). This high diversity of 18arboreal organisms has been attributed to a number of unique features of tree crowns including 19the richness of substrates (Barkman 1958, Fritz 2009) and the availability of light energy in 20comparison with the forest floor. Furthermore, pronounced environmental gradients spanning 21 from dark moist habitats in the lower to sunlit dry habitats in the upper canopy layer (Parker and 22Brown 2000) create a wealth of niches for canopy organisms. Next to a vertical niche gradient, 23the complex architecture of tree crowns also creates horizontal variation in environmental 24conditions (McCune et al. 2000). The extent of this variation is expected to change 25systematically with height (Parker and Brown 2000). In addition, and thus far not considered in 26the literature, the availability of branch surface area increases with height as the branching 27process divides a given wood volume into successively thinner branches with a higher surface to 28volume ratio. Habitat area for bark-dwelling organisms thus increases with height. According to 29positive species-area relationships (Connor and McCoy 2000) this alone should allow for higher 30diversity in the top layer of tree canopies. Using a crane facility, we developed a novel sampling 31design for canopy research with the goal to quantify the relative importance of different diversity 32generating mechanisms of epiphytic diversity in tree crowns using lichens as model organisms. 
34Epiphytic lichens represent a ubiquitous component of canopy communities. Even in temperate 35 forests the species richness of lichens may exceed that of forest trees by at least an order of 36magnitude (Ellis 2012). Here we employ arboreal lichen species as model organisms to explore 37the relative importance of mechanisms shaping patterns of biodiversity in tree crowns of two 38temperate tree species (Fraxinus excelsior L. and Quercus robur L.). We sampled lichens species 39richness ( $\alpha$ diversity) and abundance in subplots positioned in five canopy layers and at the 40trunk. The number of plots in these layers was proportional to the available bark surface area. 41The total number of species per layer is referred to as $\gamma$ diversity, their turnover between plots 42within a layer as $\beta$ diversity.

43For autotrophic organisms like lichens, radiation is inarguably a key resource and influences 44growth rates (Hilmo 2002). During leaf-on, the amount of radiation transmitted into the canopy 45decreases quickly from a shallow zone of bright light conditions at the top of the canopy to 46darker regimes in deeper canopy layers. The bottommost zone around the trunk receives only $47 a b o u t 5 \%$ of the radiation above the canopy in temperate deciduous forests (Parker 1997). 48However, in poikilohydric lichens, photosynthesis may also be quickly limited by water 49availability (Sillett and Antoine 2004). Although lichens are able to endure severe periods of 50drought, in such periods they are not metabolically active (Palmqvist 2000, Kranner et al. 2014). 51With increasing height in the canopy, lichens are exposed to drying winds and high temperatures, 52while lower canopy layers provide more sheltered microhabitats. Hence, optimal conditions for 53lichen productivity and survival might be found in intermediate crown layers where the joint 54availability of light and moisture is highest (Figure ). In this region, a higher productivity may 55sustain higher population densities. This may allow even rarer species to establish and persist 
56(Wright 1983) which in turn should lead to a higher lichen diversity in this zone, both across the 57entire crown layer ( $\gamma$ diversity) and locally at the level of subplots ( $\alpha$ diversity).

58Orthogonal to vertical environmental gradients there is also horizontal variation in environmental 59conditions. Whereas the topmost layers are fully illuminated and well-coupled with the 60atmosphere and are thus uniformly bright, dry and exposed to wind (Unterseher and Tal 2006), 61the bottom layers tend to be uniformly dark and moist. However, in the transition zone the 62complex architecture of tree crowns with their clustered branches and foliage creates a patchy 63mosaic of microsites varying in microclimate (light, rain interception, wind exposure) and 64structure (branch sizes and inclinations, bark roughness) (McCune et al. 2000, Parker and Brown 652000). The resulting horizontal variation in substrate and microclimate in mid-canopy layers may 66promote the co-occurrence of specialists each with preferences for particular habitat types 67(Connor and McCoy 2000). As a result, the $\gamma$ diversity of mid-canopy layers is expected to be 68high as a consequence of high species turnover between contrasting microsites ( $\beta$ diversity), but 69 not because of peaking $\alpha$ diversity.

70Another potentially important factor impacting composition and diversity of epiphytic 71 communities are successional changes brought forth by the emergence of new habitat surface as 72trees grow in height and produce new branches. Colonization time on young branches in the top 73canopy is shorter than on old branches further down (Ellis 2012). Furthermore, during growth, 74lichen themselves change their microenvironment by altering branch surface structure, 75facilitating further establishment and increasing moisture interception (Pypker et al. 2006) or by 76producing allelopathic compounds as competitive means (Lawrey 1986). Thus, autogenic 77successional drivers may relate to branch age (Rogers 1988, Ellis and Coppins 2006, Johansson 78et al. 2007), although the continuous growth of the host tree coincides with drastic changes in 
79microenvironment making allogenic succession more prevalent (Stone 1989). This leads to 80successional sequences of lichen community composition (Degelius 1964, 1978, Rogers 1988, 81Hilmo 1994, Wirth et al. 1999). Young top-layer branches may host lichen communities 82consisting of a limited set of fast colonizing early-successional species (Rogers 1990), while 83lichen communities on old branches, representing late stages of succession with high cover, may 84have lost species due to the exclusion by more competitive lichens and/or bryophytes 85(Armstrong and Welch 2007, Fritz 2009). As a consequence, lichen diversity is expected to 86increase from the top-layer downwards to regions where species of different successional stages 87co-occur before it decreases again (Degelius 1964, Hilmo 1994), thus creating a hump-shaped 88pattern, referred to as mid-succession peak (Johansson et al. 2007).

\section{9}

90According to the species-area relationship (SAR), a landmark theory in ecology tested for many 91taxa, habitats and scales (Connor and McCoy 2000), vertical gradients in total available branch 92surface area may strongly affect vertical patterns of $\gamma$ diversity. Although wood volume tapers 93with height to some extent, the power-law increase in surface-to-volume ratio in progressively 94thinner branches leads to a sharp increase of bark surface towards the top of the canopy. Thus, 95the major part of surface area available for epiphytes can be found in the upper canopy. 96According to SAR, this increase in available area towards the treetop should be paralleled by an 97increase in species richness. While an increase of lichen biomass with height has been reported 98(Hale 1952, Ellyson and Sillett 2003, Boch et al. 2013), we are not aware of any study 99considering SAR as potential driver of vertical patterns in lichen diversity in canopies let alone 100its component processes 'area per se', 'habitat heterogeneity' and the 'passive sampling process' 
101(Connor \& McCoy, 2000). With the SAR mechanism, $\gamma$ diversity is expected to increase 102monotonously with height.

103

104This study aims to disentangle the effects of mechanisms generating patterns of lichen diversity 105in tree canopies. With the exception of the SAR mechanism, all other mechanisms introduced 106above are hypothesized to produce a mid-canopy peak of $\gamma$ diversity at the level of canopy layers 107(Figure ) and are thus indistinguishable without additional information. However, each of the 108four mechanisms is assumed to produce a characteristic fingerprint with respect to patterns of 109diversity components such as $\alpha$ and $\beta$ diversity, gradients of trait expression and relationships to 110underlying patterns of niche predictors (see Table 1 in the method section for a summary of our 111predictions). It is important to note that the four mechanisms are not mutually exclusive. Here, 112we present a sampling design, theoretical framework and analysis scheme that allows us to 113holistically assess the relative contributions of the four mechanisms generating patterns of lichen 114diversity on two tree species of a Central European floodplain forest. To this end, we employ a 115variety of tools such as linear models, variance partitioning, null model comparisons and 116structural equation models, where processes and their underlying mechanistic hypotheses are 117represented by specific pathways.

118

119We expect to find evidence that the several mechanisms operate in parallel and mutually 120reinforce each other to produce a distinct mid-canopy peak of $\gamma$ diversity at the level of canopy 121layers. We further expect that this diversity peak is displaced upwards as a consequence of the 122SAR 'passive sampling' mechanism operating on the increasing availability of substrate area 123with height. We hope to contribute to an understanding of tree canopies as meetings points of 
bioRxiv preprint doi: https://doi.org/10.1101/2020.01.03.894303; this version posted January 3, 2020. The copyright holder for this preprint (which was not certified by peer review) is the author/funder. All rights reserved. No reuse allowed without permission.

124diversity shaping mechanisms that could explain why tree canopies are often found to be 125hotspots of biodiversity.

126

127

128 


\section{Methods}

\subsection{Study site and tree selection}

131The study was conducted at the Leipzig Canopy Crane facility (LCC). The crane site is located 132within the nature reserve "Burgaue" in the northwestern part of a floodplain forest that traverses 133the city of Leipzig in Saxony, Germany (51'20’16” N, 12²2’26” E). Leipzig lies in the transient 134area of maritime to continental climate with mean annual rainfall of $556.9 \mathrm{~mm}$ and a mean 135temperature of $9.8^{\circ} \mathrm{C}$ in average (Kaiser 2014). The crane is a LIEBHERR $71 \mathrm{EC}$ tower crane with 136a height of $40 \mathrm{~m}$ and horizontal reach of $45 \mathrm{~m}$, which is mounted on a $120 \mathrm{~m}$ railroad track. 137Thus, it provides easy access to the forest canopy within an area of 1.65 ha. At the time of 138sampling this area comprised $\sim 800$ trees with diameter at breast height $(\mathrm{DBH})>5 \mathrm{~cm}$ belonging 139to 17 species (10/ha), with Acer pseudoplatanus L., Fraxinus excelsior L. and Tilia cordata Mill. 140being the most dominant tree species. Fraxinus excelsior and a few exceptionally large 141individuals of Quercus robur L. represent the individuals with the highest basal area. Of these 142species, five large individuals each were chosen as sampling targets.

\subsection{Sampling design}

144To enable us to account for area-specific effects on lichen diversity patterns, each tree was 145subdivided into five equally spaced crown layers and a sixth trunk layer. The crown base was 146defined as the point of separation from the main trunk into erect branches having contact to the 147upper crown region. Lacking such contact, a branch was assigned to the trunk layer. Within each 148layer, sampling plots were randomly placed with a minimum distance of $1 \mathrm{~m}$ to each other. Their 149number was proportional to the share of total bark surface of the respective specific layer, 150whereby the minimum number of plots in the lowermost crown layer was set to five. The 
151available surface area within each layer was approximated by means of a Dirichlet regression 152model (Maier 2014), trained on a dataset containing biometric data collected via random branch 153sampling (Gaffrey and Saborowski 1999) originating from 385 single broadleaf trees (Riedel and 154Kändler 2017). Different models were used for modelling surface area proportions for each 155phorophyte species (S1). The F. excelsior model was using diameter at breast height (DBH) as 156predictor for a second-order polynomial model, the $Q$. robur model used a logarithmic model 157with $\mathrm{DBH}$ as predictor and the ratio crown base height / total tree height as additional predictor. 158This resulted in a total number of 55 - 99 plots per tree. Each sampling plot consisted of two 159sampling areas with dimensions of $1.5 \times 33.3 \mathrm{~cm}\left(100 \mathrm{~cm}^{2}\right.$ in total $)$ on the upward and downward 160 facing side of a branch. The dimensions have been chosen to accommodate vastly differing 161 branch diameters (range: $>1-87 \mathrm{~cm}$ ) without changing the shape of the sampling area. On the 162trunk and other vertical branches, the sampling areas were placed on opposite cardinal directions 163alternating between north/south and east/west. Sampling was carried out from October 2016 to 164July 2017. For each lichen species, cover was estimated from occurrences using a $5 \mathrm{~mm}$ grid. 165Species were identified in the field if possible. Otherwise, voucher specimens were taken for 166later identification. Identification and naming convention followed Wirth, Hauck, \& Schultz 167(2013). Some individuals of Physcia adscendens and P. tenella could not be determined at the 168species level due to insufficiently developed soralia and were thus grouped under Physcia sp. 169Note: this species aggregate does not include other species of the same genus, like P. stellaris. In 170two cases identification completely failed. These species were noted by their description (for 171 example "sterile grey crustose lichen"). As additional parameters for each sampled branch the 172height above ground, diameter, inclination and distance and azimuth to the trunk was recorded 173using measuring tapes or calipers, an inclinometer, a laser rangefinder VERTEX VL 5 (HAGLÖF, 
174Järfälla, Sweden) and a compass respectively. Branch age was modelled from branch diameter 175and species using a data set of branch cross sections collected off fallen trees in the area (S2). 176Bark roughness was estimated categorically according to an ordinal scale ranging from 1 177 (smooth) to 6 (rough). Bark lesions and deadwood were noted. Leaf area index (LAI) was 178measured at the plot level in August and September 2018 using a Plant Canopy Analyzer LAI1792200C (LI-COR, Lincoln, NE, U.S.A.).

\subsection{Tracing the mechanistic pathways}

181The following hypothesized mechanisms are tested for their influence on driving epiphytic lichen 182diversity in the tree crown: (i) Habitat optimality, (ii) Succession, (iii) Habitat Heterogeneity and 183(iv) Species Area Relations (SAR). We propose that each of the four mechanisms produces a 184characteristic fingerprint with respect to the height gradients and correlations patterns of its 185diversity components $(\alpha, \beta, \gamma)$, gradients of trait expression and relationships to underlying 186patterns of niche predictors, which are summarized in Table 1. These mechanisms are not 187mutually exclusive, but presumed to interfere and interact with each other.

188For the Optimality mechanism to operate, a mid-canopy $\gamma$ diversity peak has to occur which is 189driven by a peaking $\alpha$ diversity, i.e. $\gamma$ and mean $\alpha$ diversity are correlated at the canopy-layer 190level. It is further presumed that $\alpha$ diversity is related to one or several relevant environmental 191 predictors. The optimal conditions should also be reflected by a higher cover of lichens. Under 192the Optimality mechanism one would not expect a positive relationship between the within-layer 193variability of environmental variables and $\gamma$ diversity and no systematic species turnover along 194the vertical canopy gradient.

195The Succession mechanism is expected to produce a mid-canopy $\gamma$ diversity peak driven by a 196peaking $\alpha$ diversity as above. It is an additional necessary condition that that there is a systematic 
197species turnover along the gradient of branch age, as a proxy of successional time. There also 198needs to be systematic species turnover along the vertical canopy gradient, as mean successional 199time decreases with height, making plots within a layer more similar to each other than plots in 200other layers. Consistent with the Succession mechanism is a positive correlation of within-layer $201 \beta$ diversity and the variation in branch age.

202The Habitat Heterogeneity mechanism is expected to produce a mid-canopy $\gamma$ diversity peak that 203is driven by a peaking $\beta$ diversity, but not $\alpha$ diversity as in the first two mechanisms mentioned 204above. As $\alpha$ and $\beta$ diversity are often correlated (Chase et al. 2011), this implies that observed 205dissimilarities between layers have to exceed the level of dissimilarity expected by a baseline $\alpha-\beta$ 206correlation. It is a necessary condition that $\beta$ diversity is positively correlated with variation in 207habitat variables (inclination and bark roughness, LAI) pointing to niche diversity within layers. 208For the SAR mechanism to operate according to the passive sampling hypothesis sensu Connor \& 209McCoy (1979), where a higher surface area acts as larger sample for colonists, $\gamma$ diversity should 210correlate with available substrate area per layer and thus should peak in the top canopy layer. $211 \gamma$ diversity can be independent of either $\alpha$ or $\beta$ diversity. If available area is a strong determinant 212for species diversity, its peak may be skewed towards the top of the crown. In contrast, the 213Optimality, Succession and Heterogeneity mechanisms all may predict a richness peak towards 214the mid crown, as this region may offer a more balanced mix of sheltered, yet light habitats 215(McCune et al. 2000, Parker and Brown 2000), a transition zone from early to late successional 216species (Rogers 1988, Hilmo 1994) and environmentally and architecturally more diverse 217habitats respectively.

218Those and further assumptions made by each hypothesis are laid out in Table 1 and Figure 2. 


\subsection{Analysis}

222Data Analysis was carried out in in R, version 3.5.1 (R Core Team 2018). In this study, species 223richness on plot level is referred to as $\alpha$ diversity while layer-level species richness is referred to 224as $\gamma$ diversity. As real abundances in terms of individual counts are hard to estimate in lichen 225without resorting to molecular methods (Snäll et al. 2004, Walser et al. 2005, Gjerde et al. 2012), 226within this study abundances are represented as cover. Within-layer $\beta$ diversity was calculated on 227incidence data using the Simpson-based multiple-site dissimilarity (Baselga 2010). A 228composition index was calculated as first axis of a non-metric multidimensional scaling (nMDS) 229ordination using the function metaMDS implemented in the vegan package (Oksanen et al. 2302019). The number of dimensions (k) was deliberately set to one to generate a single 231compositional gradient (variable 'com' in Figure 3). Goodness of fit was evaluated using the 232stressplot function from the same package, in which $\mathrm{R}^{2}$ is defined as $1-S^{2}$, with $\mathrm{S}$ being the 233stress value, which is a measure based on the sum of squared residuals of the ordination 234(Legendre and Legendre 2003 p. 447 ff.). The nMDS ordination was based on a $\beta$ diversity 235matrix, which used pairwise between-plot dissimilarities based on the Simpson $\beta$ diversity index 236( $\beta_{\text {sim }}$; Koleff, Gaston, \& Lennon, 2003).

\subsubsection{Multiple linear regression model}

238An important distinction between the hypotheses is whether variation in $\gamma$ diversity and mean $\alpha$ 239diversity are closely connected (Optimality, Succession) or whether patterns in $\gamma$ diversity are an 240emergent property at the layer level either driven by variation in $\beta$ diversity (Heterogeneity) or 241area $(S A R)$. To get insight into this question a multiple linear regression model was created using 242a z-transformed layer-level data set with $\gamma$ diversity as response variable and mean $\alpha$ diversity, $\beta$ 
243diversity and available surface area as explanatory variables. Additionally, the interaction terms

244of area with mean $\alpha$ and $\beta$ diversity were included. This allowed us to assign a potential area 245effect to one of its composite mechanisms heterogeneity or area per se which make different 246predictions about their scale of impact (Schoereder et al. 2004).

\subsubsection{Piecewise Structural Equation Model}

248To test for the plausibility of aforementioned mechanisms of shaping biodiversity patterns being 249expressed at the plot level ( $\alpha$ diversity) piecewise structural equation modelling (SEM) was 250applied. This analysis was performed for the pooled phorophyte species dataset and on datasets 251 containing only a single phorophyte species, separately. The SEM model was constructed using 252the piecewiseSEM package in R (Lefcheck 2016). Numerical data had been either log- or tukey253transformed using the rcompanion package (Mangiafico 2019), if the transformation improved 254residual normal distribution of the models used within the SEM and subsequently standardized 255(z-score). Exponents used for transformation are provided in the supplement (S3). Global model 256fit was evaluated using the Fisher's C. The Fisher's C statistic is derived of the combined p257values of each independence claim associated with the hypothesized path diagram of the SEM, 258known as the basis set (Lefcheck 2016). A test of directed separations (Shipley 2013) was 259performed on the model to test for missing possible paths, which upon inclusion would lead to an 260improvement of the model. Such improvements of the model were compared against the initial 261 model using the Akaike's information criterion (AIC) as calculated by Shipley (2013).

262

263The piecewise SEM was constructed with $\alpha$ diversity as main target variable (Figure 3). SEMs 264feature exogenous variables and endogenous variables, the first of which are variables without 265incoming causal relations within the model. The latter are defined as being caused by other 
266variables. Endogenous variables may also mediate causal relations to further endogenous 267variables. Exogenous variables on the plot level include branch age as linear and quadratic term, 268branch inclination and LAI in both a linear and quadratic term. The inclusion of both linear and 269quadratic terms for branch age and LAI was based on the expectation of a hump-shaped relation 270of species richness according to the mid-successional diversity peak and a hump-shaped 271productivity-diversity relationship, respectively. Originally, bark roughness was included as 272additional exogenous variable to capture small scale local variation in branch surface 273environment, but it was dismissed due to its high correlation with branch age (Spearman 274 correlation coefficient $=0.83$ ). All endogenous variables within the plot level are dependent on 275all the aforementioned exogenous variables. These are the composition index, cover and $\alpha$ 276diversity. Branch inclination and LAI are assumed to have implications for the energy budget of 277epiphytic lichen and thus are expected to show significant relations towards $\alpha$ diversity under the 2780ptimality mechanism (Figure 2). As under this assumption species richness is regulated via 279higher population densities a strong link between cover and $\alpha$ diversity can also be expected. 280Branch age can be expected to be a strong determinant for the sequential establishment of lichen 281 communities along the successional gradient. The composition of these communities in turn is 282intended to be captured with the composition index. The Succession mechanism hypothesis 283(Figure ) predicts an overlap of distinct early and late successional communities at the mid 284successional peak, which is translated into a link of the community indicator towards $\alpha$ diversity. 285As the shape of this relationship can expected to be hump-shaped, the quadratic composition 286index is added as predictor for $\alpha$ diversity as well. Thus, the piecewise SEM is constructed based 287on three linear models: 


$$
\begin{aligned}
& \text { com } a_{0}+a_{1} \cdot \text { branch age }+a_{2} \cdot \text { inclination }+a_{3} \cdot L A I \\
& \text { cover } b_{0}+b_{1} \cdot \text { branch }+b_{2} \cdot(\text { branchage })^{2}+b_{3} \cdot \text { inclination }+b_{4} \cdot L A I+b_{5} \cdot(L
\end{aligned}
$$

$\alpha$ diversity $c_{0}+c_{1} \cdot$ branchage $+c_{2} \cdot(\text { branchage })^{2}+c_{3} \cdot$ inclination $+c_{4} \cdot L A$

289With com referring to the composition index and $a, b$ and $c$ to the estimated slopes of equation 1 , 2902 and 3, respectively. In order to highlight potential idiosyncrasies of the phorophyte species, this 291SEM is calculated on both the full data set as well as separately for each species.

\subsubsection{Distance-based redundancy analysis}

293A distance-based redundancy Analysis (dbRDA, Legendre \& Anderson, 1999) was applied to the

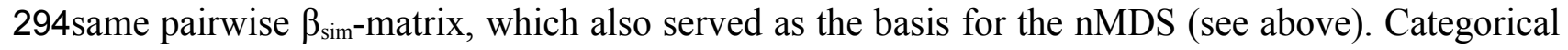
295identity properties (phorophyte species, layer) as well as environmental and structural properties 296(branch age, inclination, bark roughness, LAI, height and distance to the tree center) were used 297to delineate variation in turnover and community composition both spatially and mechanistically. 298Variance partitioning (S8) was applied to check for significance and quantify explained variation 299of these predictors.

\subsubsection{Raup-Crick Null model}

301In studies comparing $\alpha$ and $\beta$ diversities, both measures are usually expected to be correlated to 302some degree, as many $\beta$ metrics can vary simply due to changes in either $\alpha$ or $\gamma$ diversity (Chase 303et al. 2011). Null model approaches can be used to disentangle and correct for this correlation. 304Furthermore, these null models offer insight into the mechanistic signature of $\beta$ diversities, as the 305correlation between $\alpha$ diversity and a given $\beta$ diversity metric offers a null expectation which 306observed $\beta$ diversities may fall below or exceed. In our case, $\beta$ diversities within layer higher 307than expected may hint towards deterministic species sorting processes between communities as 308expected with the Habitat Heterogeneity mechanism; $\beta$ diversities within a layer lower than 
309expected may hint towards deterministic sorting processes that operate across layers, for example 310along a successional gradient. The model used in this study was originally devised by Raup \& 311Crick (1979) and modified by Chase et al. (2011) and has been applied in numerous studies

312(Muñoz et al. 2004, Zhou et al. 2014, Dini-Andreote et al. 2015). It provides an index ranging 313from -1 (communities are more similar than expected by random chance) to 1 (communities are 314more dissimilar than expected by random chance) with a value of 0 corresponding to the Null 315 expectation.

\subsubsection{Species trait variance analysis}

317Successional series of lichens are often reflected by changes in trait composition (Rogers 1990, 318Lawrey 1991). Early successional species tend to have smaller thalli and reproduce sexually and 319with smaller diaspores. Late succession species achieve competitiveness through faster growth 320rates and are defended against herbivores, pathogens and UV radiation by secondary metabolites 321(Lawrey 1986, Ellis 2012). For all observed lichen species an average value of the composition 322index could be computed using the presence/absence data for each plot. If the composition index 323adequately represents a successional gradient, this would yield the species average position on 324this gradient. These species averages were modelled in a variance analysis against species traits 325known to reflect a successional trait gradient (Rogers 1990), such as growth form, dispersal 326strategy and their reaction to chemical identification tests as a proxy for chemical traits (K-,C327and P-test), to check for significant trait gradients. 


\section{Results}

330A total number of 27 lichen species was recorded $(17 \pm 2.5$ species per individual tree; for a 331 complete list see S4). Out of these, 20 species occurred on both phorophyte species. Four species 332were exclusive to $F$. excelsior and three species to $Q$. robur.

333Species richness patterns were similar between both phorophyte species, differing more between 334layers than between tree individuals or tree species (Figure 4). In both $\alpha$ and $\gamma$ diversity a general 335increase with height could be observed with a sharp decrease in the topmost layer. Trunks were 336almost devoid of any lichen growth with only 7 species found there and $61.3 \%$ empty plots 337compared to $3.8 \%$ in all crown layers. Layer 4 was the most species-rich layer in all trees, 338containing all but 5 of the recorded species. On both plot and layer level, species richness was 339significantly correlated with lichen cover (Spearman; $\alpha: 0.65 ; \gamma: 0.68$; both $p<0.001$ ). Within340layer $\beta$ diversity was lowest on the trunks and in layer 5. Values for the inner crown layers were 341 not significantly different from each other (Kruskal-Wallis; $\mathrm{p}=0.66 ; \mathrm{p}<0,001$ for all layers). 342Correlations between the environmental and structural predictors (age, bark roughness, branch 343inclination and LAI) were generally high and significant,but most pronounced between branch 344age and bark roughness (Spearman; Fraxinus: 0.90, Quercus: 0.91; $<<0.001$ ), and branch age 345and LAI (Spearman; Fraxinus: 0.66, Quercus: 0.67; p <0.001).

\subsection{Multiple linear regression}

347In the multiple regression modeling $\gamma$ diversity as a function of mean $\alpha$ diversity, $\beta$ diversity and 348area (including interactions), mean $\alpha$ diversity had the strongest effect $(0.87, \mathrm{p}<0.001)$, with the 349only other significant effect being the interaction term of $\alpha$ diversity and area $(0.31, p=0.002)$. 
350Available surface area (Figure 5) alone only had a small, non-significant effect $(0.12, \mathrm{p}=0.10)$. 351Overall explained variance was $82.4 \%$.

\subsection{Piecewise Structural Equation Model}

353The SEM exploring the determinants of $\alpha$ diversity using the full data set, including both 354phorophyte species, obtained a non-significant Fisher's C (8.52, p = 0.384), indicating an 355appropriate representation of the data. The tree species-specific models performed similarly well 356(F. excelsior: $7.726, \mathrm{p}=0.461 ;$ Q. robur: $10.784, \mathrm{p}=0.214)$.

357Branch age was the exogenous parameter with the strongest significant effect on all plot-level 358dependent variables (Figure 6) with concave quadratic relations towards $\alpha$ diversity $(-0.20, \mathrm{p}<$ 3590.001; linear term: $-0.11, \mathrm{p}=0.002)$ and cover $(-0.50, \mathrm{p}<0.001$; linear term non-significant $)$ and 360linear relations towards community composition $(-0.67, \mathrm{p}<0.001)$. Yet, cover constituted the 361strongest predictor for $\alpha$ diversity $(0.63, \mathrm{p}<0.001)$. LAI had significant effects on $\alpha$ diversity 362(linear: -0.06, $\mathrm{p}=0.033$ ), cover (linear: $-0.23, \mathrm{p}<0.001$, quadratic: $-0.11, \mathrm{p}<0.001$ ) and 363community composition (linear: $-0.08, \mathrm{p}=0.026$ ), while branch inclination only affected 364community composition significantly $(0.09, \mathrm{p}=0.001)$. The effect of community composition on $365 \alpha$ diversity was non-significant. Variance explained in endogenous variables was $72 \%(\alpha$ 366diversity), $40 \%$ (cover) and $52 \%$ (community composition).

367The species-specific models (S7) confirmed the main patterns of the full model, although they 368diverged in a few aspects. While the number of significant paths was slightly reduced in the 369model for F. excelsior, the model for $Q$. robur included one additional significant path compared 370to the full model, a negative linear effect of branch age on cover. As a consequence, both hump371shaped branch age relations towards $\alpha$ diversity and cover were shifted slightly towards younger 
372 branches in $Q$. robur with a maximum of the species richness-branch age relation at $41 \pm 6$ years 373 compared to $50 \pm 3$ years in $F$. excelsior ( $45 \pm 6$ years in all trees).

\subsection{Distance-based Redundancy analysis}

375Pairwise between-plot species turnover (dbRDA, overall $34.9 \%$ explained variance) varied 376mainly between layers (26.8\% variance explained, $4.0 \%$ purely attributed to layer with no 377overlap to other effects, see Figure 9), with plots of different layers having a significantly higher $378 \beta$ diversity than plots within layers of equal height (Wilcoxon; $\mathrm{p}<0.001$ ). All crown 379environmental variables were significant predictors of pairwise $\beta$ diversity, such as branch 380inclination $(p=0.003)$, LAI $(p=0.010)$ and especially branch age $(p<0.001)$, except for bark 381roughness, which did not explain additional variation in $\beta$ diversity and was thus removed from 382the model. They generally shared high overlap with layer. This might imply that these factors are 383in part responsible for between layer differences. Branch age, for example, explained $25.1 \%$ of 384variation in pairwise $\beta$ diversity, $22.7 \%$ of which was shared with layer (which also includes $38513.9 \%$ overlap with LAI), while $2.4 \%$ of variation was purely attributed to branch age. 386Phorophyte species explained a comparably small amount of variation (5.5\%) but displayed very 387little overlap with other effects.

\subsection{Raup-Crick Null Model}

389Within layers, the number of shared species between plots was significantly higher than null 390model expectations (t-test, $\mathrm{p}<0.001)$ resulting in mostly negative within-layer means of the 391Raup-Crick metric $(-0.36 \pm 0.26$, Figure 8). This implies within-layer homogeneity and thus $\gamma$ 392diversity control by raised levels of $\alpha$ diversity rather than $\beta$ diversity. Exceptions could mainly 393be found on the trunk, where the observed number of shared species mainly matched null model 
394expectations $(-0.08 \pm 0.10)$. Deviations from the null model where highest in layer $5(-0.62 \pm$ 3950.12). The increase in deviation from the trunk to the uppermost layers diverged in shape 396between the tree species with the increase being steeper in F. excelsior compared to Q. robur.

\subsection{Species composition and Species trait variance analysis}

398Foliose lichens constituted the most common growth form in both species numbers (13) and total 399cover. Crustose lichens (10) were less abundant. Leprous species were fewer in number of 400species (3) but had amongst them one of the most abundant species Candelariella xanthostigma 401(Ach.) Lettau. Finally, only three fruticose species could be observed, all of them in small 402numbers and restricted to only three tree individuals. The $\mathrm{nMDS}(\mathrm{k}=1, \mathrm{n}=652)$ conducted in 403order to create the composition index produced a stress value of 0.26 (non-metric $\mathrm{R}^{2}$ of 0.93 ). 404The composition index itself showed negative correlations towards branch age (see fig. 11; 405Spearman: $-0.70 ; p<0.001$ ) and LAI (Spearman: $-0.51 ; p<0.001$ ) but was independent of 406branch inclination (Spearman: $-0.06 ; p=0.140$ ). Variations in the averages of the composition 407index for each species were best explained by growth form $(33.3 \%$, including $16.3 \%$ unshared 408explained variation; $\mathrm{p}=0.002)$ and presence of Apothecia $(30.0 \%$, including $12.7 \%$ unshared 409explained variation; $p=0.020$ ). Other traits in regards to dispersal mode or chemistry did not 410contribute significant explanation of variance in composition (all $\mathrm{p}>0.2$ ).

411 


\section{Discussion}

413Several lines of evidence have been investigated in order to trace the influence of Optimality, 414Succession, Heterogeneity and SAR as mechanisms shaping patterns in lichen diversity in the tree 415crown (Table 3). The emergence of the gradients in richness and composition due to these 416mechanisms are not necessarily mutually exclusive, but may have interactions and added effects, 417and are discussed in the following subsections. While criteria for the Optimality and Succession 418mechanisms were generally met, we could not find any evidence for the Heterogeneity 419mechanism. The SAR mechanism was only weakly and indirectly supported: area did not 420influence $\gamma$ diversity directly, but had a significant interaction term with $\alpha$ diversity.

\subsection{Optimality}

423Both $\alpha$ and $\gamma$ diversity exhibited a mid-canopy peak and were significantly correlated (criterion 4241, Table 1). In contrast, a distinct peak in $\beta$ diversity was not observed and $\beta$ diversity was not 425correlated with $\gamma$ diversity. An increase in $\alpha$ diversity was expected to be mediated by an increase 426in cover (criterion 3, Table 1). This was supported by the SEM, where cover was the strongest 427predictor of $\alpha$ diversity (Figure 6). Cover itself depended significantly on LAI (criterion 2, Table 4281), displaying a hump-shaped relationship. Notably, this includes a decrease of cover on old 429branches in the dim lower part of the trunk, on which sufficient time for colonization without 430light limitation could have created a high lichen cover (compare 4.2). Lichens, being 431photoautotrophic organisms, certainly depend on available light in the canopy. It has been shown 432to be a significant predictor for species richness of epiphytic lichens (Gustafsson and Eriksson 4331995, Fritz et al. 2009, Moning et al. 2009, Normann et al. 2010, Rosabal et al. 2012). However, 
434other microclimatic factors like water limitation can be of overriding importance (Sillett and 435Antoine 2004, Rambo 2010). While we did not measure humidity, we expected that water 436limitation is highest in the top crown due to drying winds and higher irradiation leading to 437suboptimal growing conditions thus creating the observed hump-shape. The strong signal of 438Optimality emphasizes the importance of growing seasons conditions for lichen diversity 439patterns, because during the leaf-off period neither light nor humidity gradients are particularly 440pronounced.

\subsection{Succession}

442In the piecewise SEM, branch age was not only an important determinant of species richness 443(Figure 10) but also of species composition (criterion 4, Table 1). It even outperformed LAI as 444predictor of both cover and richness. After accounting for height layer and phorophyte species, 445pairwise differences in composition between plots (dbRDA, see 3.3) also were best explained by 446branch age (criterion 6, Table 1). Moreover, species composition was expected to be more 447similar within layers than between layers (criterion 7, Table 1), which was supported by both the 448dbRDA variance partitioning and the Raup-Crick null model deviations. In the first case, the 449majority of variation was attributed to height layers. In the second case, excluding the trunk, 450within-layer deviations of the Raup-Crick null model were mostly negative, indicating that plots 451within layers were more similar than expected by chance.

452Evidence for succession further requires branch age to be connected to a successional sequence 453of epiphytic lichen (Degelius 1964, Hilmo 1994, Wirth et al. 1999), expressing a systematic trait 454gradient (criterion 5, Table 1). Most common pioneers comprise of physically smaller crustose or 455foliose lichen with lower investments in longevity. These typically settle on the first uneven 456surfaces like bud scars and joints (Degelius 1964, Rogers 1990, Ellis 2012). This could be 
457observed in this study and growth form was the trait that best explained the compositional 458gradient. Common species found in the top canopy layer included small, intricate foliose species 459(i.e. genus Physcia and Xanthoria) and crustose species like Amandinea punctata (Hoffm.) 460Coppins \& Scheid. Smooth branch surfaces were mainly colonized by small rosettes of crustose 461species (e.g. genus Lecanora and Caloplaca). Another typical trait for pioneers is the ability to 462efficiently disperse propagules in order to colonize new sites (Rogers 1990, Armstrong and 463Welch 2007). The presence of apothecia did also explain the compositional gradient, with 464species developing apothecia being more prevalent on younger branches. Apothecia produce 465sexual spores that are much smaller and hence are dispersed more readily than asexual modes of 466dispersal (soredia, isidia and thallus fragments). Bigger, more robust foliose species, fruticose 467and leprous species with predominantly asexual modes of dispersal appeared further down on 468relatively older branches and the trunk.

469One caveat remained: The hump-shaped relation between branch age and $\alpha$ diversity (Figure 11) 470might suggest a mid-succession peak at a branch age of about 45 years. However, the decline in 471species richness on the peak's descent is assumed to result from competitive exclusions 472(Purschke et al. 2013), also described as "quorum effect" (Jenkins 2006). Evidence for 473competitive interactions, such as overgrowth between lichens could not be observed on the lower 474parts of the crown and the trunk. On the contrary, lichen thalli became more sparsely distributed 475and the cover decreased (Figure 10b) making competitive exclusion less probable. This is in line 476with previous studies on epiphytic lichens which concluded that competitive exclusions rarely 477occurs once thalli are established (Lawrey 1991, Snäll et al. 2003, Pentecost 2014).

478In conclusion, the Succession mechanism aptly describes the increase in species richness as 479environmental filters get alleviated and species accumulate on the surfaces of growing branches 
480that are gradually overtopped and sheltered as the tree gains height. Past the species richness 481maximum, however, a different mechanism than competitive exclusion has to account for the 482decrease in cover and species richness on the oldest parts of the tree. As possible alternative 483mechanisms competition by bryophytes, shedding of bark surface (Cáceres et al. 2007) or 484grazing pressure by gastropods (Asplund et al. 2010) have been suggested. However, the 485coinciding decrease in environmental Optimality and of lichen cover on older branches in lower 486canopy layers despite the long time for colonization, hinting towards less favorable conditions 487further below (see 4.1) might be the strongest candidate.

\subsection{Heterogeneity}

489Heterogeneity is amongst the first and the most commonly documented drivers of diversity 490(Stein et al. 2014). The horizontal variation of environmental variables has been highlighted as 491distinct ecological feature of tree crowns (Parker and Brown 2000) and as driver of arboreal 492diversity patterns. This has been exemplified for tropical vascular epiphytes (Woods et al. 2015). 493It is thus surprising that in our study heterogeneity showed little to no influence in shaping the 494diversity gradient within the trees.

495Firstly, $\beta$ diversity was not related to $\gamma$ diversity (criterion 8 , Table 1 ) and secondly, deviations 496from the Raup-Crick null model did not indicate that within-layer differences were higher than 497expected by chance. Both would have been prerequisites for the Heterogeneity mechanism. 498Although variation in pairwise $\beta$ diversity was reasonably well explained in the dbRDA, little 499variation was attributed to within-layer variation of environmental variables (criterion 9, Table 5001). Out of $34.9 \%$ explained variation, $26.2 \%$ could at least partially ascribed to height layers, $5014.4 \%$ to phorophyte species, leaving only about $4 \%$ remaining to be explained. 


\subsection{Species Area Relationship}

503In the multiple linear regression analysis, only mean $\alpha$ diversity and its interaction with area had 504a significant effect on $\gamma$ diversity. Available surface area was not significant as a main effect 505(criterion 10, Table 1). Thus, area does not have an effect at the layer level, but it amplifies the 506effect of $\alpha$ diversity in layers with a high amount of surface area. This may suggest that area does 507 have an influence on small scale processes of species richness regulation in line with the area 508per se - hypothesis (Connor and McCoy 2000, Schoereder et al. 2004). However, layers in the 509upper crown not only possess greater branch surface area; they also are less shaded and span a 510greater extent of projected area. As a result, they are able to collect more photosynthetically 511active radiation. The interaction effect of surface area may thus also contain elements of the 512Optimality mechanism.

\subsection{Conclusion and implications for lichen biodiversity in canopies}

514The results of this study suggest an intricate interplay between the mechanisms of environmental 515Optimality and Succession in controlling vertical diversity patterns of epiphytic lichen in the tree 516crown. This includes environmental limitations in the harshly exposed young branches and dim 517understory (Optimality), as well as the strong vertical species turnover associated with 518successional dynamics in the upper height layers. On older branches in height layer four both 519mechanisms jointly create a sheltered, yet light habitat where a majority of species of the whole 520successional gradient co-occur to create the observed peak in species richness. The strong 521increase in surface area with height resulting from the fractal branching process did not translate 522into a monotonously increasing diversity signal. While we found horizontal heterogeneity within 523height layers to have little effect, vertical heterogeneity in environmental conditions and 524successional time appeared to be strong driver of lichen diversity and composition in our study 
525(compare Figure 7) and in the literature (Bates 1992, McCune et al. 2000). These gradients may 526be steeper than elevational gradients by an order of magnitude (Nakamura et al. 2017) and thus 527have the potential to strongly contribute to the creation of the biodiversity hotspots that are forest 528canopies (Ozanne et al. 2003, Nakamura et al. 2017).

\subsection{Outlook}

530It comes as little surprise that the effects of mechanisms such as Succession and Optimality were 531hard to disentangle. Not only because they are found to be mechanistically intertwined, but so 532are the predictors used to describe energetic as well as age relations. LAI and branch age were 533significantly correlated as the architecture of the tree itself is responsible in shaping the vertical 534gradients found within the canopy (McCune et al. 2000). Such correlations put limits on the 535insights that can be gained in observational studies. Experiments which separate both effects, for 536instance by distributing standardized $\operatorname{logs}$ as lichen habitat along the vertical and horizontal 537gradient (Antoine and McCune 2006), offer a way to separate and quantify the relative 538importance of mechanisms like Succession, Optimality as well as surface area relationships and 539dispersal. Effects of dispersal limitations were not included in the original hypotheses as lichen 540are considered to have a generally high dispersal ability at the canopy scale we considered 541(Muñoz et al. 2004, Lenoir et al. 2012). However, evidence for small scale dispersal limitations 542does exists, in particular in dependence of propagule size (Sillett et al. 2000, Löbel et al. 2006). 543We propose to install air traps collecting diaspores and use the knowledge of lichen distribution 544to infer dispersal kernels depending on diaspore size. Finally, lichens are a ubiquitous element of 545biodiversity in temperate tree crowns but by far only one of many. To date, only limited 546literature exists on multi-taxa approaches on multi-trophic dynamics (Shorrocks et al. 1991, 547Nadkarni 1994, Lamit et al. 2015, Asplund et al. 2016). It certainly would be of interest to 
548investigate how the patterns of lichen diversity found within this study propagate through the 549complex ecosystem that is the forest canopy including diversity patterns of lichen-associated 550organisms as well as processes such as nutrient cycling. Facilities such as the Canopy Crane in 551Leipzig are promising tools to tackle this challenge.

552

553 


\section{Acknowledgments}

555We would like to thank Antonia Ludwig, Joy Opitz and Cordelia Weis for their help with fieldwork, 556Dr. Peter Otto for providing access to the herbarium universitatis lipsiensis and sharing his expertise on 557determining lichens. We further thank Prof. Dr. Volkmar Wirth for helpful comments and his pioneering 558contributions to the field of lichen taxonomy and ecology without which this study would not have been 559possible and Christian Vonderach for the provision of the dataset of random branch sampling, which 560allowed us to quantify gradients in available branch area, and finally the German Centre for Integrative 561Biodiversity Research (iDiv) for supporting the Leipzig Canopy Crane Facility. 


\section{References}

565Antoine, M. E., and B. McCune. 2006. Contrasting Fundamental and Realized Ecological Niches with 566 Epiphytic Lichen Transplants in an Old-Growth Pseudotsuga Forest. The Bryologist 107:163-172. 567Armstrong, R. A., and A. . Welch. 2007. Competition in lichen communities: Review article. Symbiosis $568 \quad 43: 1-12$.

569Asplund, J., Y. Gauslaa, S. Merinero, and R. J. Carlos. 2016. The role of fungal parasites in tri-trophic 570 interactions involving lichens and lichen-feeding snails. New Phytologist.

571Asplund, J., P. Larsson, S. Vatne, and Y. Gauslaa. 2010. Gastropod Grazing Shapes the Vertical

572 Distribution of Epiphytic Lichens in Forest Canopies. Journal of Ecology 98:218-225.

573Barkman, J. J. 1958. Phytosociology and Ecology of Cryptogamic Epiphytes. Page The Bryologist. Van 574 Gorcum Comp. N.V.

575Baselga, A. 2010. Partitioning the turnover and nestedness components of beta diversity. Global Ecology 576 and Biogeography 19:134-143.

577Bates, J. W. 1992. Influence of Chemical and Physical Factors on Quercus and Fraxinus Epiphytes at 578 Loch Sunart, Western Scotland: A Multivariate Analysis. The Journal of Ecology 80:163.

579Boch, S., J. Müller, D. Prati, S. Blaser, and M. Fischer. 2013. Up in the tree--the overlooked richness of 580 bryophytes and lichens in tree crowns. PLoS One 8:e84913.

581Cáceres, M. E. S., R. Lücking, and G. Rambold. 2007. Phorophyte specificity and environmental 582 parameters versus stochasticity as determinants for species composition of corticolous crustose

583 lichen communities in the Atlantic rain forest of northeastern Brazil. Mycological Progress 6:117584136.

585Chase, J. M., N. J. B. Kraft, K. G. Smith, M. Vellend, and B. D. Inouye. 2011. Using null models to 586 disentangle variation in community dissimilarity from variation in $\alpha$-diversity. Ecosphere 2. 587Connor, E. F., and E. D. McCoy. 2000. Species - Area Relationships.

588Degelius, G. 1964. Biological studies of the epiphytic vegetation on twigs of Fraxinus excelsior. Elanders. 589Degelius, G. 1978. Further studies on the epiphytic vegetation on twigs. Gothoburgensia, Botanica.

590Dini-Andreote, F., J. C. Stegen, J. D. van Elsas, and J. F. Salles. 2015. Disentangling mechanisms that 591 mediate the balance between stochastic and deterministic processes in microbial succession.

592 Proceedings of the National Academy of Sciences 112:E1326-E1332.

593Ellis, C. J. 2012. Lichen epiphyte diversity: A species, community and trait-based review. Perspectives in 594 Plant Ecology, Evolution and Systematics 14:131-152.

595Ellis, C. J., and B. J. Coppins. 2006. Contrasting functional traits maintain lichen epiphyte diversity in 596 response to climate and autogenic succession. Journal of Biogeography 33:1643-1656.

597Ellyson, W. J. T., and S. C. Sillett. 2003. Epiphyte Communities on Sitka Spruce in an Old-Growth

598 Redwood Forest. A Journal of Bryology And Lichenology 106:197-211.

599Fritz, Ö. 2009. Vertical distribution of epiphytic bryophytes and lichens emphasizes the importance of old 600 beeches in conservation. Biodiversity and Conservation 18:289.

601Fritz, Ö., J. Brunet, and M. Caldiz. 2009. Interacting effects of tree characteristics on the occurrence of

602 rare epiphytes in a Swedish beech forest area. The Bryologist 112:488-505.

603Gaffrey, D., and J. Saborowski. 1999. RBS, ein mehrstufiges Inventurverfahren zur Schätzung von

604 Baummerkmalen. I. Schätzung von Nadel-und Asttrockenmassen bei 66-jährigen Douglasien.

605 Allgemeine Forst-und Jagdzeitung 170:177-183.

606Gjerde, I., H. H. Blom, L. Lindblom, M. S. Ctersdal, and F. H. Schei. 2012. Community assembly in

607 epiphytic lichens in early stages of colonization 93:749-759.

608Gustafsson, L., and I. Eriksson. 1995. Factors of importance for the epiphytic vegetation of aspen Populus

609 tremula with special emphasis on bark chemistry and soil chemistry. Journal of applied

610 ecology:412-424.

611Hale, M. E. 1952. Vertical distribution of cryptogams in a virgin forest in Wisconsin. Ecology 33:398- 
612406.

613Hamilton, A. J., Y. Basset, K. K. Benke, P. S. Grimbacher, S. E. Miller, V. Novotný, G. A. Samuelson,

614 N. E. Stork, G. D. Weiblen, and J. D. L. Yen. 2010. Quantifying uncertainty in estimation of tropical

615 arthropod species richness. American Naturalist 176:90-95.

616Hilmo, O. 1994. Distribution and succession of epiphytic lichens on Picea abies branches in a boreal

617 forest, central norway. Lichenologist 26:149-169.

618Hilmo, O. 2002. Growth and morphological response of old-forest lichens transplanted into a young and 619 an old Picea abies forest. Ecography 25:329-335.

620Jenkins, D. G. 2006. In Search of Quorum Effects in Metacommunity Structure: Species Co-Occurrence

621 Analyses. Ecology 87:1523-1531.

622Johansson, P., H. Rydin, and G. Thor. 2007. Tree age relationships with epiphytic lichen diversity and

623 lichen life history traits on ash in southern Sweden. Ecoscience 14:81-91.

624Kaiser, F. 2014. Klimadiagramm des Leipziger Instituts für Meteorologie.

625Koleff, P., K. J. Gaston, and J. J. Lennon. 2003. Measuring beta diversity for presence-absence data.

626 Journal of Animal Ecology 72:367-382.

627Kranner, I., R. Beckett, A. Hochman, T. H. N. Iii, and R. Beckett. 2014. Desiccation-tolerance in lichens :

628 a review. The Bryologist 111:576-593.

629Lamit, L. J., P. E. Busby, M. K. Lau, Z. G. Compson, T. Wojtowicz, A. R. Keith, M. S. Zinkgraf, J. A.

630 Schweitzer, S. M. Shuster, C. A. Gehring, and T. G. Whitham. 2015. Tree genotype mediates

631 covariance among communities from microbes to lichens and arthropods. Journal of Ecology

$632 \quad 103: 840-850$.

633Lawrey, J. D. 1986. Biological Role of Lichen Substances. The Bryologist 89:111-122.

634Lawrey, J. D. 1991. Biotic interactions in lichen community development: A review. The Lichenologist

$635 \quad 23: 205-214$.

636Lefcheck, J. S. 2016. piecewiseSEM: Piecewise structural equation modeling in R for ecology, evolution,

637 and systematics. Methods in Ecology and Evolution 7:573-579.

638Legendre, P., and M. J. Anderson. 1999. Distance-based redundancy analysis: Testing multispecies

639 responses in multifactorial ecological experiments. Ecological Monographs 69:1-24.

640Legendre, P., and L. Legendre. 2003. Numerical Ecology. Second edition.

641Lenoir, J., R. Virtanen, J. Oksanen, L. Oksanen, M. Luoto, J. A. Grytnes, and J. C. Svenning. 2012.

642 Dispersal ability links to cross-scale species diversity patterns across the Eurasian Arctic tundra.

643 Global Ecology and Biogeography 21:851-860.

644Löbel, S., T. Snäll, and H. Rydin. 2006. Species richness patterns and metapopulation processes--

645 evidence from epiphyte communities in boreo-nemoral forests. Ecography 29:169-182.

646Maier, M. J. 2014. DirichletReg: Dirichlet Regression for Compositional Data in R:26.

647Mangiafico, S. 2019. rcompanion: Functions to Support Extension Education Program Evaluation.

648McCune, B., R. Rosentreter, J. M. Ponzetti, and D. C. Shaw. 2000. Epiphyte habitats in an old conifer

649 forest in western Washington, USA. The Bryologist 103:417-427.

650Moning, C., S. Werth, F. Dziock, C. Bässler, J. Bradtka, T. Hothorn, and J. Müller. 2009. Lichen diversity

651 in temperate montane forests is influenced by forest structure more than climate. Forest ecology and

652 management 258:745-751.

653Muñoz, J., Á. M. Felicísimo, F. Cabezas, a R. Burgaz, and I. Martínez. 2004. Wind as a Long-Distance

654 Dispersal Vehicle in the Southern Hemisphere. Science 304:1144-1147.

655Nadkarni, N. M. 1994. Diversity of Species and Interactions in the Upper Tree Canopy of Forest

656 Ecosystems. Amer. Zool. 34:70-78.

657Nakamura, A., R. L. Kitching, M. Cao, T. J. Creedy, T. M. Fayle, M. Freiberg, C. N. Hewitt, T. Itioka, L.

658 P. Koh, K. Ma, Y. Malhi, A. Mitchell, V. Novotny, C. M. P. Ozanne, L. Song, H. Wang, and L. A.

659 Ashton. 2017. Forests and Their Canopies: Achievements and Horizons in Canopy Science. Elsevier

660 Ltd.

661Normann, F., P. Weigelt, C. Gehrig-Downie, S. R. Gradstein, H. J. M. Sipman, A. Obregon, and J.

662 Bendix. 2010. Diversity and vertical distribution of epiphytic macrolichens in lowland rain forest 
663 and lowland cloud forest of French Guiana. Ecological Indicators 10:1111-1118.

664Oksanen, J., F. G. Blanchet, M. Friendly, R. Kindt, P. Legendre, D. McGlinn, P. R. Minchin, R. B.

665 O'Hara, G. L. Simpson, P. Solymos, M. H. H. Stevens, E. Szoecs, and H. Wagner. 2019. vegan:

666 Community Ecology Package.

667Ozanne, C. H. P., D. Anhuf, S. L. Boulter, H. Keller, R. L. Kitching, C. Körner, F. C. Meinzer, A. W.

668 Mitchell, T. Nakashizuka, P. L. Silva Dias, N. E. Stork, S. J. Wright, and M. Yoshimura. 2003.

669 Biodiversity meets the atmosphere: A global view of forest canopies. Science 301:183-186.

670Palmqvist, K. 2000. Carbon economy in lichens. The New Phytologist 148:11-36.

671Parker, G. G. 1997. Canopy structure and light environment of an old-growth Douglas-fir/Western

672 Hemlock forest. Northwest Science 71:261-270.

673Parker, G. G., and M. J. Brown. 2000. Forest canopy stratification -is it useful? The American Naturalist

$674 \quad 155: 473-484$.

675Pentecost, A. 2014. The cryptogamic epiphytes of ash (Fraxinus excelsior L.) in an ancient pasture-

676 woodland: Relationships with some environmental variables of relevance to woodland epiphyte

677 management. Cryptogamie, Bryologie 35:19-36.

678Purschke, O., B. C. Schmid, M. T. Sykes, P. Poschlod, S. G. Michalski, W. Durka, I. Kühn, M. Winter,

679 and H. C. Prentice. 2013. Contrasting changes in taxonomic, phylogenetic and functional diversity

680 during a long-term succession: Insights into assembly processes. Journal of Ecology 101:857-866.

681Pypker, T. G., M. H. Unsworth, and B. J. Bond. 2006. The role of epiphytes in rainfall interception by

682 forests in the Pacific Northwest. I. Laboratory measurements of water storage. Canadian Journal of

683 Forest Research 36:809-818.

684R Core Team. 2018. R: A Language and Environment for Statistical Computing. Vienna, Austria.

685Rambo, T. R. 2010. Structure and composition of corticolous epiphyte communities in a Sierra Nevada

686 old-growth mixed-conifer forest. The American Bryological and Lichenological Society 113:55-71.

687Raup, D. M., and R. E. Crick. 1979. Paleontological Society Measurement of Faunal Similarity in

688 Paleontology Author ( s ): David M. Raup and Rex E . Crick Published by: SEPM Society for

689 Sedimentary Geology Stable URL: http://www.jstor.org/stable/1304099 REFERENCES Linked

690 references are a. Journal of Paleontology 53:1213-1227.

691Riedel, T., and G. Kändler. 2017. Nationale Treibhausgasberichterstattung: Neue Funktionen zur

692 Schätzung der oberirdischen Biomasse am Einzelbaum. Forstarchiv 88:31-38.

693Rogers, R. W. 1988. Succession and survival strategies in lichen populations on a palm trunk. The Journal

694 of Ecology 76:759-776.

695Rogers, R. W. 1990. Ecological strategies of lichens. The Lichenologist 22:149-162.

696Rosabal, D., A. R. Burgaz, A. Altamirano, and G. Aragón. 2012. Differences in diversity of corticolous

697 lichens between interior and edge of the Monte Barranca semi-deciduous forest, Santiago de Cuba.

698 The Bryologist 115:333-340.

699Schoereder, H., C. Galbiati, C. R. Ribas, T. G. Sobrinho, C. F. Sperber, O. Desouza, and C. Lopes-

700 andrade. 2004. Should we use proportional sampling for species - area studies? Journal of

$701 \quad$ Biogeography 31:1219-1226.

702Shipley, B. 2013. The AIC model selection method applied to path analytic models compared using a d-

703 separation test. Ecology 94:560-564.

704Shorrocks, B., J. Marsters, I. Ward, and P. J. Evennett. 1991. The fractal dimension of lichens and the

705 distribution of arthropod body lengths. Functional Ecology:457-460.

706Sillett, S. C., and M. E. Antoine. 2004. Lichens and Bryophytes in Forest Canopies. Pages 151-174

$707 \quad$ Forest Canopies: Second Edition.

708Sillett, S. C., B. McCune, J. E. Peck, T. R. Rambo, and A. Ruchty. 2000. Dispersal limitations of

709 epiphytic lichens result in species dependent on old-growth forests. Ecological applications 10:789-

710799.

711Snäll, T., J. Fogelqvist, P. J. Ribeiro JR, and M. Lascoux. 2004. Spatial genetic structure in two

712 congeneric epiphytes with different dispersal strategies analysed by three different methods.

713 Molecular Ecology:2109-2119. 
bioRxiv preprint doi: https://doi.org/10.1101/2020.01.03.894303; this version posted January 3, 2020. The copyright holder for this preprint (which was not certified by peer review) is the author/funder. All rights reserved. No reuse allowed without permission.

714Snäll, T., P. J. Ribeiro Jr, and H. Rydin. 2003. Spatial occurrence and colonisations in patch-tracking 715 metapopulations: local conditions versus dispersal. Oikos 103:566-578.

716Stein, A., K. Gerstner, and H. Kreft. 2014. Environmental heterogeneity as a universal driver of species 717 richness across taxa, biomes and spatial scales. Ecology Letters 17:866-880.

718Stone, D. F. 1989. Epiphyte Succession on Quercus garryana Branches in the Willamette Valley of 719 Western Oregon. Bryologist 92:81-94.

720Unterseher, M., and O. Tal. 2006. Influence of small scale conditions on the diversity of wood decay 721 fungi in a temperate, mixed deciduous forest canopy. Mycological research 110:169-178.

722Walser, J. C., R. Holderegger, F. Gugerli, S. E. Hoebee, and C. Scheidegger. 2005. Microsatellites reveal 723 regional population differentiation and isolation in Lobaria pulmonaria, an epiphytic lichen.

724 Molecular Ecology 14:457-467.

725Wirth, V., R. Cezanne, and M. Eichler. 1999. Contribution to the Knowledge of Dynamics of Epiphytic 726 Lichens. Stuttgarter Beiträge zur Naturkunde:1-17.

727Wirth, V., M. Hauck, and M. Schultz. 2013. Die Flechten Deutschlands. Ulmer.

728Woods, C. L., C. L. Cardelús, and S. J. Dewalt. 2015. Microhabitat associations of vascular epiphytes in a 729 wet tropical forest canopy. Journal of Ecology 103:421-430.

730Wright, D. H. 1983. Species-Energy Theory: An Extension of Species-Area Theory. Oikos 41:496.

731Zhou, J., Y. Deng, P. Zhang, K. Xue, Y. Liang, J. D. Van Nostrand, Y. Yang, Z. He, L. Wu, D. A. Stahl, 732 T. C. Hazen, J. M. Tiedje, and A. P. Arkin. 2014. Stochasticity, succession, and environmental 733 perturbations in a fluidic ecosystem. Proceedings of the National Academy of Sciences 111:E836-

734 E845.

735

736 


\section{Table 1}

738Table 1: Evidence matrix: Expected observations according to each hypothesized mechanism.

739The first column details were in the crown a peak in diversity is to be expected and which

740measure or scale of biodiversity will be affected. Here, 'mid crown' does not necessarily refer to

741 the mathematical midpoint of the crown but rather may be slanted to either top or bottom of the

742canopy. The second and third column feature conditions that have to be observed necessarily or

743are indicative of a mechanism, respectively. Symbols and abbreviations used are: $\alpha, \beta, \gamma=\alpha, \beta$

744or $\gamma$ diversity; com $=$ community composition; $A=$ branch surface area; $P=$ habitat predictors

745(e.g. branch inclination, LAI); age = branch age, 'traits' is referring to a successional species

746trait gradient; $i=$ layer marker, $j=$ plot marker $\left(j_{a}\right.$ and $j_{b}$ mark different layers). The numbers

747following the conditions in the third and fourth column are for reference in Figure 2.

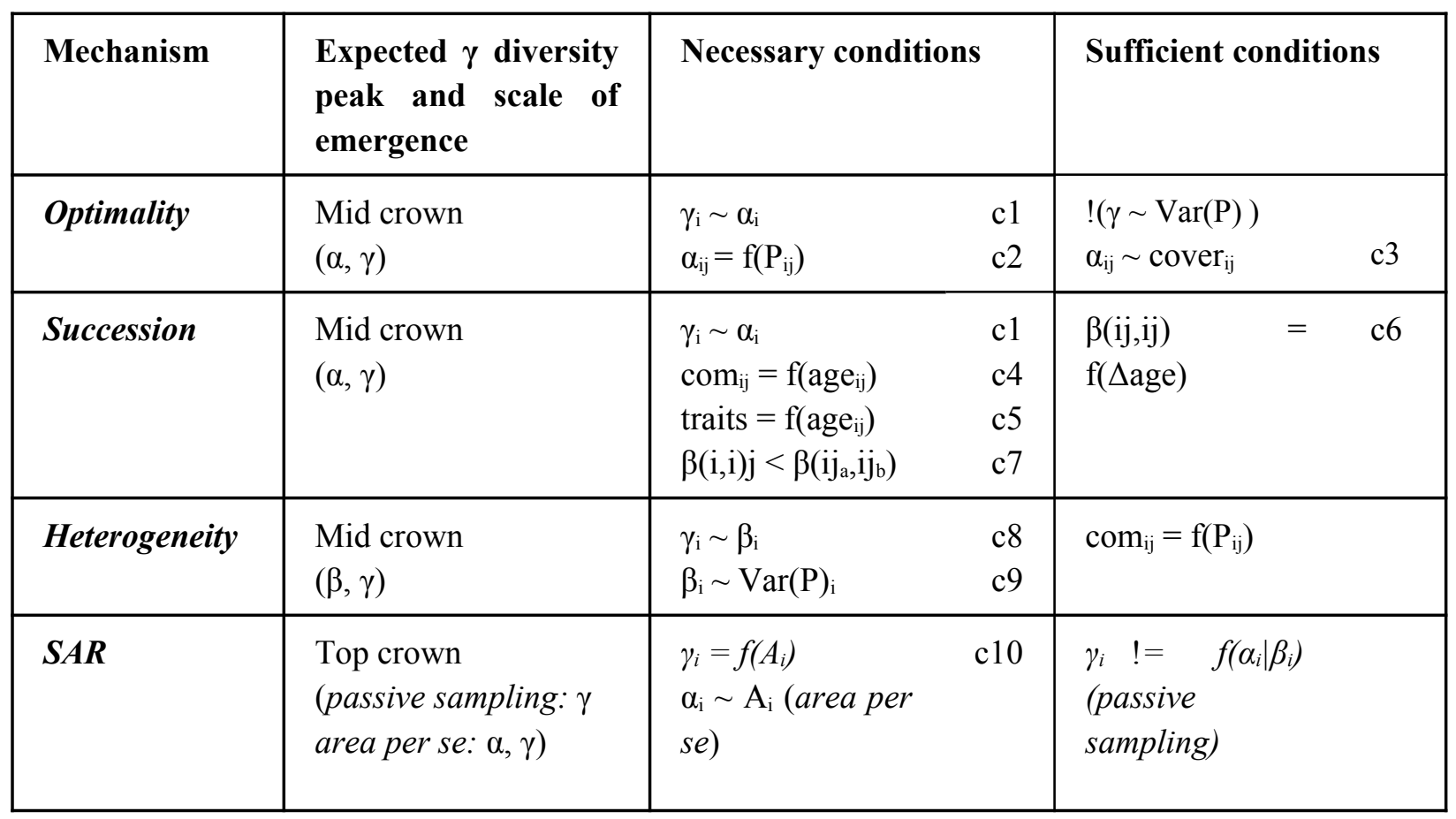

748 


\section{Table 2}

750Table 2: Used statistical methods by reference number (white on black) and criteria from Table

7512 to be tested (reference in brackets)

\begin{tabular}{|l|l|l|}
\hline reference number & model type & Aim \\
\hline $\mathbf{1}$ & $\begin{array}{l}\text { multiple linear regression } \\
\text { model }\end{array}$ & $\begin{array}{l}\text { test contributions of mean } \alpha \\
\text { and } \beta \text { diversity and area to } \gamma \\
\text { diversity }(\mathrm{c} 1, \mathrm{c} 8, \mathrm{c} 10)\end{array}$ \\
\hline $\mathbf{2}$ & $\begin{array}{l}\text { piecewise structural equation } \\
\text { model }\end{array}$ & $\begin{array}{l}\text { contributions to } \alpha \text { diversity } \\
\text { (c2,c3,c4) }\end{array}$ \\
\hline $\mathbf{3}$ & $\begin{array}{l}\text { distance-based redundancy } \\
\text { analysis }\end{array}$ & $\begin{array}{l}\text { contributions of } \\
\text { environmental variation to } \\
\text { beta diversity (c6, c9) }\end{array}$ \\
\hline $\mathbf{4}$ & Raup-Crick Null model & $\begin{array}{l}\text { delineate } \beta \text { diversity } \\
\text { characteristics independent } \\
\text { of } \alpha \text { diversity variation } \\
\text { (c7,c8) }\end{array}$ \\
\hline $\mathbf{5}$ & $\begin{array}{l}\text { test for a successional trait } \\
\text { gradient (c5) }\end{array}$ \\
\hline
\end{tabular}

752

753 


\section{Table 3}

755Table 3: Criteria from the evidence matrix (Table 1) with information about their support by the 756results. Symbols and abbreviations used are: $\alpha, \beta, \gamma=\alpha, \beta$ or $\gamma$ diversity; com $=$ community

757composition; $A=$ branch surface area; $P=$ habitat predictors (e.g. branch inclination, LAI);

758age = branch age, 'traits' is referring to a successional species trait gradient; $i=$ layer marker, $759 j=$ plot marker ( $j_{a}$ and $j_{b}$ mark different layers). The criterion numbers are for reference in 760Figure 2.

\begin{tabular}{|c|c|c|c|}
\hline Mechanism & \multicolumn{2}{|c|}{ Criterion } & Support \\
\hline \multirow[t]{3}{*}{ Optimality } & $\mathrm{c} 1$ & $\gamma_{\mathrm{i}} \sim \alpha_{\mathrm{i}}$ & Yes \\
\hline & $\mathrm{c} 2$ & $\alpha_{\mathrm{ij}}=\mathrm{f}\left(\mathrm{P}_{\mathrm{ij}}\right)$ & Yes \\
\hline & $\mathrm{c} 3$ & $\alpha_{i j} \sim \operatorname{cover}_{i j}$ & Yes \\
\hline \multirow[t]{5}{*}{ Succession } & $\mathrm{c} 1$ & $\gamma_{\mathrm{i}} \sim \alpha_{\mathrm{i}}$ & Yes \\
\hline & $\mathrm{c} 4$ & $\operatorname{com}_{\mathrm{ij}}=\mathrm{f}\left(\mathrm{age}_{\mathrm{ij}}\right)$ & Yes \\
\hline & $\mathrm{c} 5$ & traits $=\mathrm{f}\left(\right.$ age $\left._{\mathrm{ij}}\right)$ & Yes \\
\hline & & $\begin{array}{l}\beta(\mathrm{ij}, \mathrm{ij}) \quad= \\
\mathrm{f}(\Delta \text { age })\end{array}$ & Yes \\
\hline & $\mathrm{c} 7$ & $\beta(\mathrm{i}, \mathrm{i}) \mathrm{j}<\beta\left(\mathrm{ij}_{\mathrm{a}}, \mathrm{ij} \mathrm{j}_{\mathrm{b}}\right)$ & Yes \\
\hline \multirow[t]{2}{*}{ Heterogeneity } & $\mathrm{c} 8$ & $\gamma_{\mathrm{i}} \sim \beta_{\mathrm{i}}$ & No \\
\hline & c9 & $\beta_{\mathrm{i}} \sim \operatorname{Var}(\mathrm{P})_{\mathrm{i}}$ & Weak, mainly supported by branch age (see c6) \\
\hline$S A R$ & $\mathrm{c} 10$ & $\gamma_{i}=f\left(A_{i}\right)$ & $\begin{array}{l}\text { Weak, significant interaction with } \alpha \text { diversity, but } \\
\text { no direct effect on } \gamma \text { diversity }\end{array}$ \\
\hline
\end{tabular}

761 


\section{Figure legends}

763Figure 1: Schematic representation of the interplay between biodiversity shaping mechanisms 764(columns) and their expected spatial fingerprints on layer-level species richness ( $\gamma$ diversity, 765represented as encircled number in the center). Each smaller square represents a sampling unit 766area within a layer (bigger square). Optimality: Concurrence of environmental variables such as 767available light and humidity leads to favorable growth conditions in a mid-canopy layer. 768Heterogeneity: Differentially adapted species (indicated by different color gradients) coexist in a 769more heterogeneous layer in the mid crown. Succession: Early and late successional species 770(indicated by different color gradients) coincide on branches of median age opposed to young 771 branches in the top crown layer and old branches in the bottom layer. Species Area Relation 772(SAR): The creation of surface area due to continuous branching along the vertical axis leads to a 773species-indiscriminate increase in richness.

774

775Figure 2: Conceptual scheme of hypothesized mechanisms for the emergence of lichen diversity 776in the tree crown. Rounded boxes represent the mechanism itself, square boxes measurable 777variables. Numbers in small white boxes refer to expected conditions in the evidence matrix 778(Table 1), numbers inside black boxes refer to statistical methods used (detailed in table 2).

779

780Figure 1: piecewise structural equation model for the plot level. Mechanistic distinctions can be 781made according to the path followed (The numbers correspond to conditions mentioned in Table 7821 and Figure 2). According to the optimality hypothesis, paths in the lower half (2,3; marked red) 783should be more distinguished as species richness is thought to be driven by energetic optimality 
784and mediated by abundance, represented by leaf area index (LAI) and cover, respectively. If $\alpha$ 785diversity is mainly determined by successional mechanisms species richness is expected to 786depend strongly on branch age, mediated by species composition (respective pathways marked 787blue). For each branch age, LAI and composition index both the linear and quadratic term are 788included to account for hump shaped patterns. No mechanistic distinction can be stated for either 789heterogeneity or Species area relation hypothesis as these are assumed to be emergent at the 790layer level.

791

792Figure 4: Vertical patterns of lichen diversity in the tree crown. White boxes represent 793individuals of Fraxinus excelsior, grey boxes Quercus robur. a) $\gamma$ diversity (layer level) b) $\alpha$ 794diversity (plot level) c) $\beta$ diversity (within layer)

795

796Figure 5: Modelled amount of available surface area within layers in relation to total tree surface. 797White boxes represent Fraxinus excelsior, grey boxes Quercus robur. Note the amount of 798variation in surface area being visibly higher in $Q$. robur.

799

800Figure 6: piecewise SEM of plot level pathways using the full dataset. $\mathrm{R}^{2}$ in small boxes in top 801right; arrow width is proportional to parameter estimates, straight lines indicate regressions, 802double-headed, curved arrows covariance dotted lines $\mathrm{p}<0.1$, full lines $\mathrm{p}<0.05$, grey lines $\mathrm{p}>$ 8030.1 plot marker (j); layer marker (i). See supplement S7 for species specific models.

804

805Figure 7: Variation partitioning of $\beta$ diversity (dbRDA). The bars represent total explained 806variation by respective variables as the sum of its pure effect and overlap shared with other 
807variables. Blank portions of the bars represent the pure effect; black portions represent the sum 808of shared overlaps each explaining less than $1 \%$ of variance in $\beta$ diversity. Overall explained 809variation: $34.9 \%$ (65.1\% unexplained).

810

811Figure 8: Raup-crick model: mean Raup-Crick metric [-1,1] value by layer and tree species. A 812value close to 1 represents communities more dissimilar than expected in the null model, 813indicating community assembly to be highly deterministic (environmental filtering) within 814layers. Negative values represent communities more similar compared to the null model, 815indicating assembly processes to be highly deterministic across layers with the communities 816within the layer being more similar than expected by chance, while values close to zero conform 817with null expectations and indicate stochastic community assembly.

818

819Figure 9: Species trait relations towards branch age. Grey triangles (Fraxinus excelsior) and 820empty circles (Quercus robur) represent sampling plots in a 2D composition by branch age 821ordination. The composition index is calculated as first axis of a non-metric multidimensional 822scaling (nMDS) based on a pairwise $\beta$ diversity matrix. Species means for both the nMDS axis 823as well as branch age determine species position in this $2 \mathrm{D}$ ordination, represented by the colored 824symbols. Noteworthy, a trend for spore-dispersed, crustose and small foliose lichens to be 825aligned to younger branches, whereas species in which vegetative dispersal is more common are 826increasingly prevalent with increasing branch age.

827

828Figure 10: Both the $\alpha$ diversity and cover - branch age relationship shows a distinct hump shape 
bioRxiv preprint doi: https://doi.org/10.1101/2020.01.03.894303; this version posted January 3, 2020. The copyright holder for this preprint (which was not certified by peer review) is the author/funder. All rights reserved. No reuse allowed without permission.

829 Figure 1

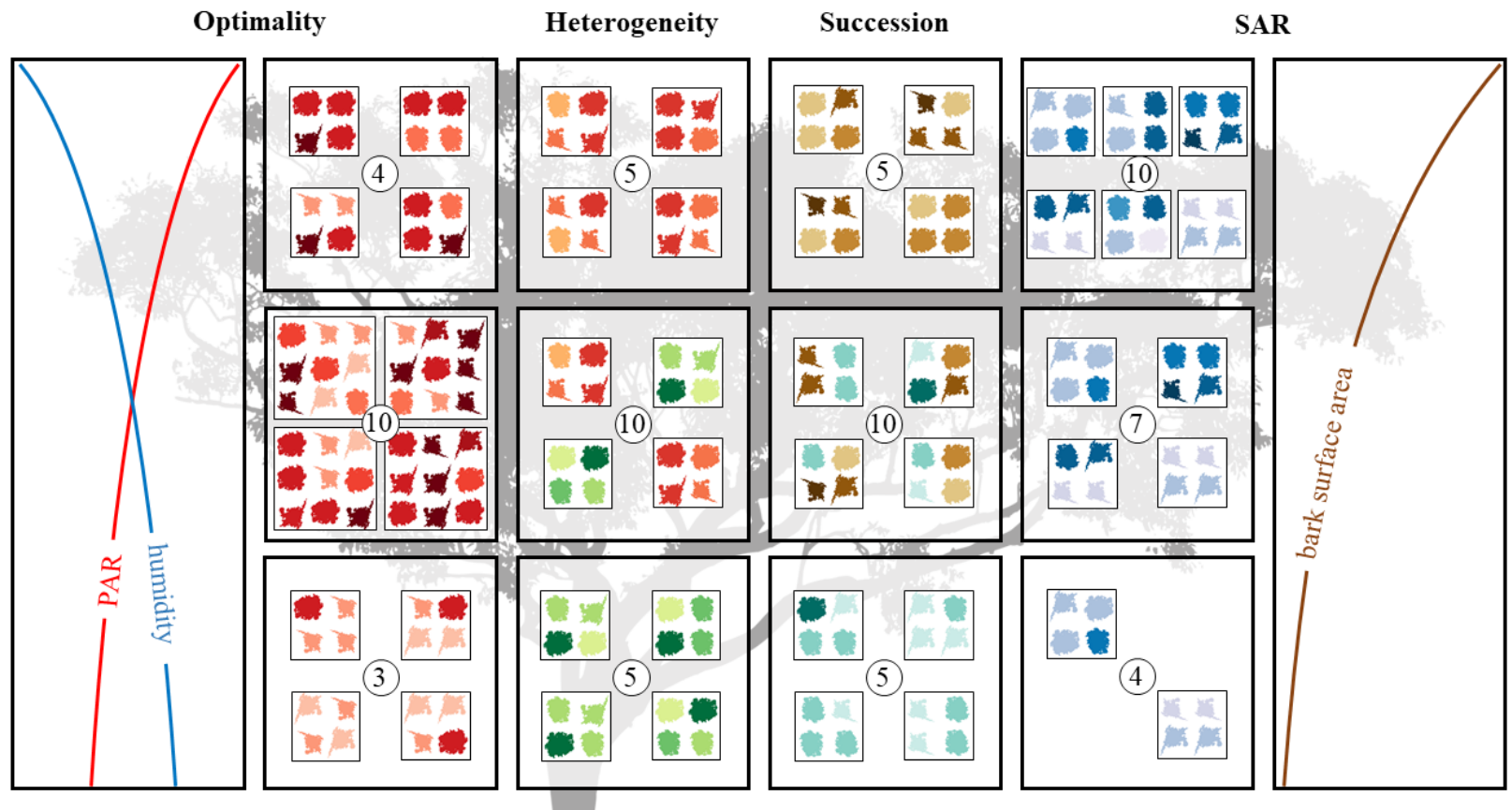

830 


\section{$831 \quad$ Figure 2}

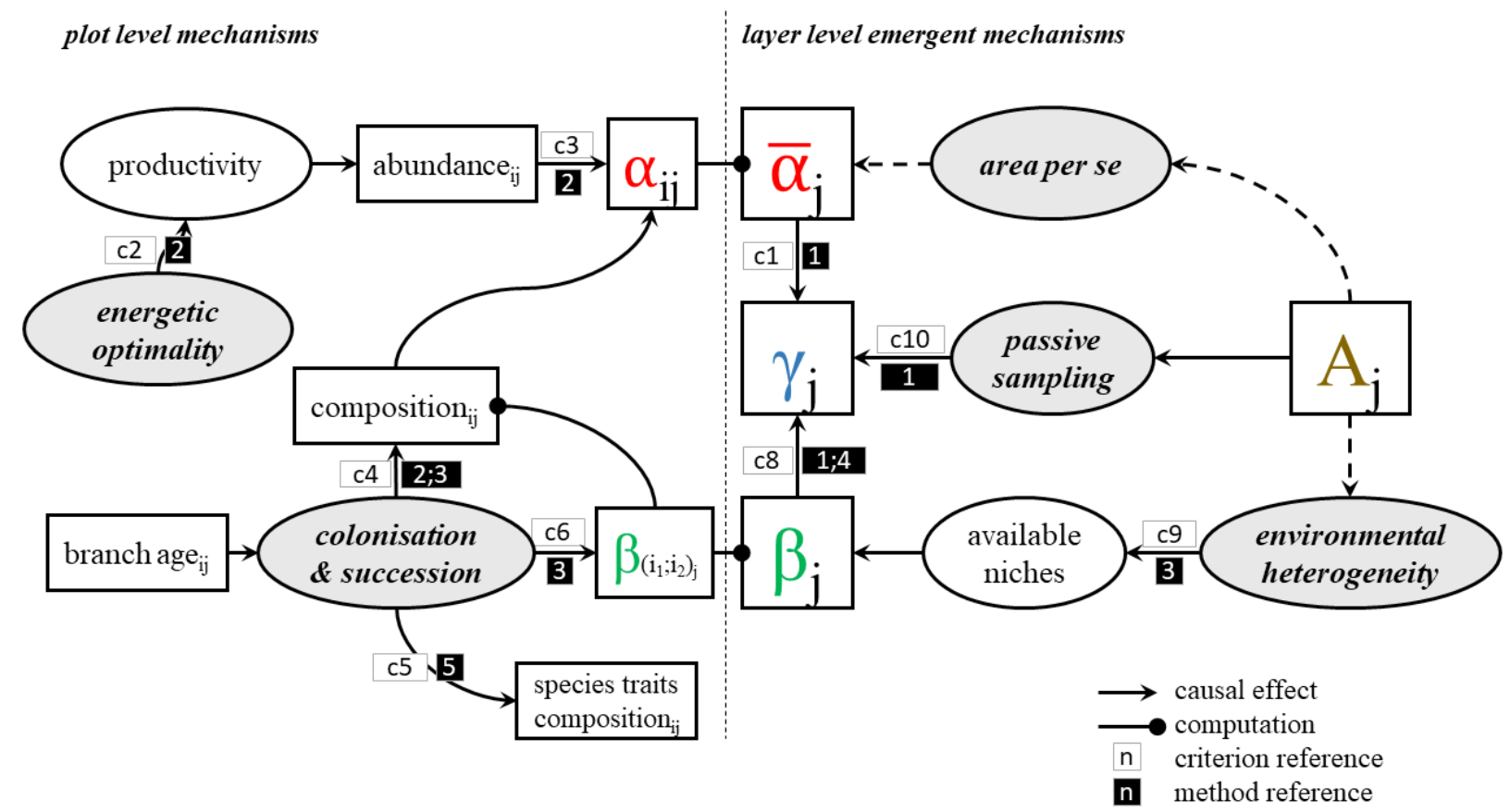

832 
bioRxiv preprint doi: https://doi.org/10.1101/2020.01.03.894303; this version posted January 3, 2020. The copyright holder for this preprint (which was not certified by peer review) is the author/funder. All rights reserved. No reuse allowed without permission.

$833 \quad$ Figure 3

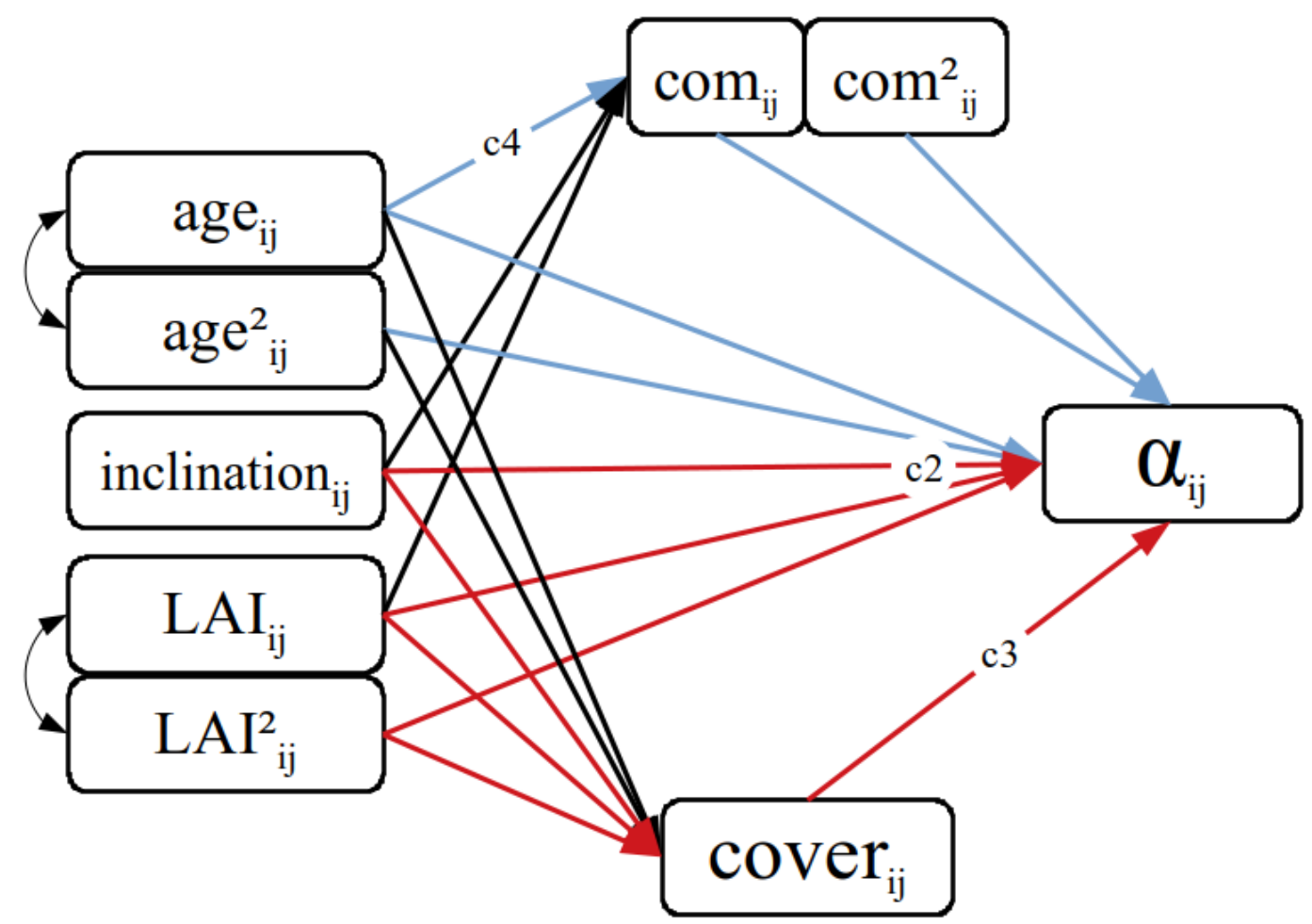

834

835 


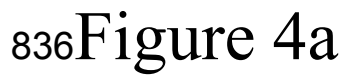

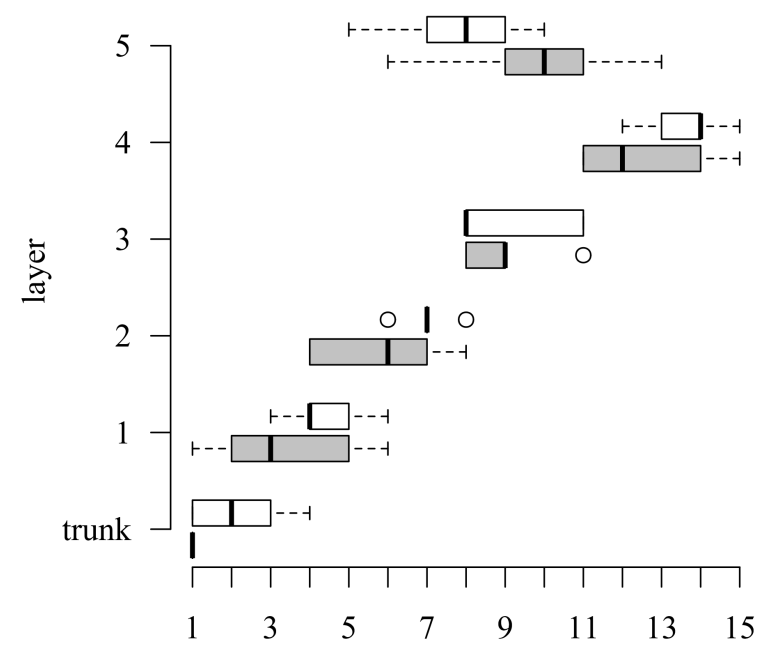

837

species richness 
bioRxiv preprint doi: https://doi.org/10.1101/2020.01.03.894303; this version posted January 3, 2020. The copyright holder for this preprint (which was not certified by peer review) is the author/funder. All rights reserved. No reuse allowed without permission.

\section{Figure $4 b$}

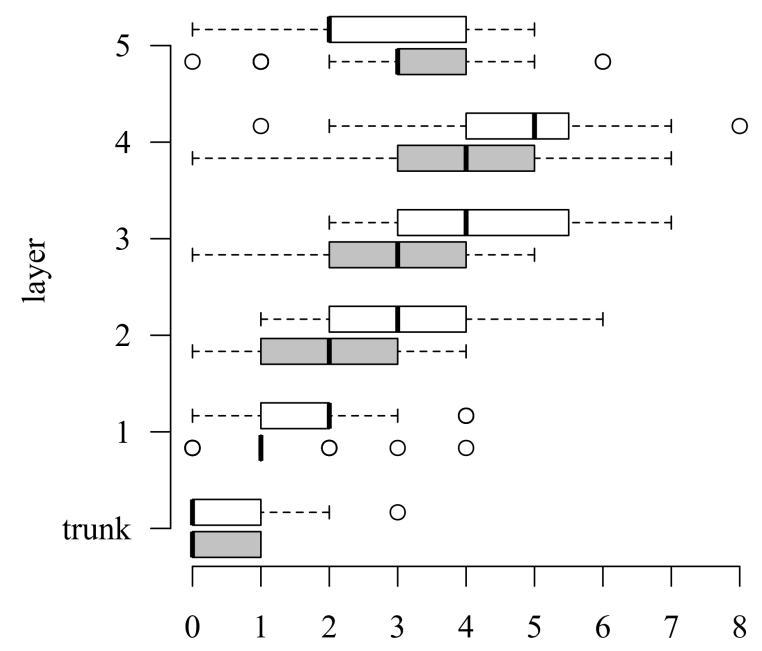

839

species richness 


\section{Figure $4 \mathrm{c}$}

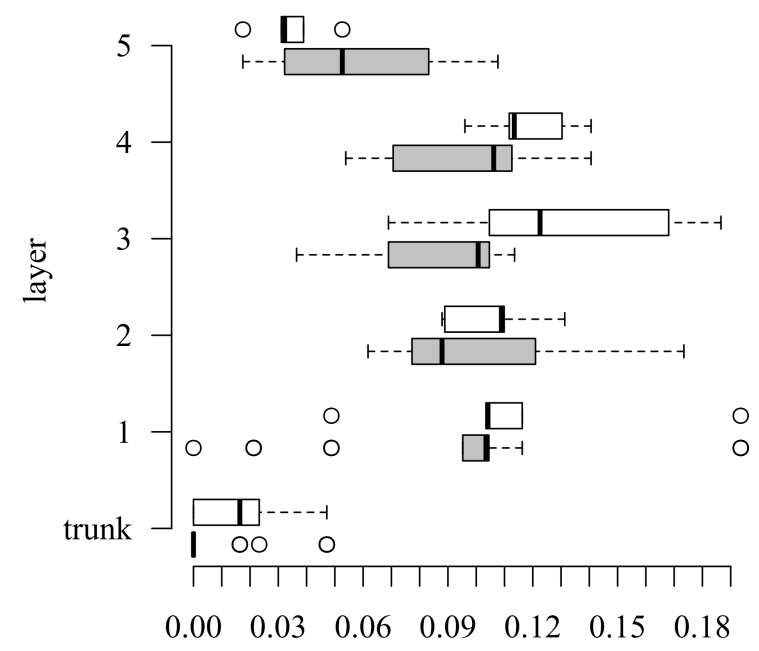

841

842 
bioRxiv preprint doi: https://doi.org/10.1101/2020.01.03.894303; this version posted January 3, 2020. The copyright holder for this preprint (which was not certified by peer review) is the author/funder. All rights reserved. No reuse allowed without permission.

\section{Figure 5}

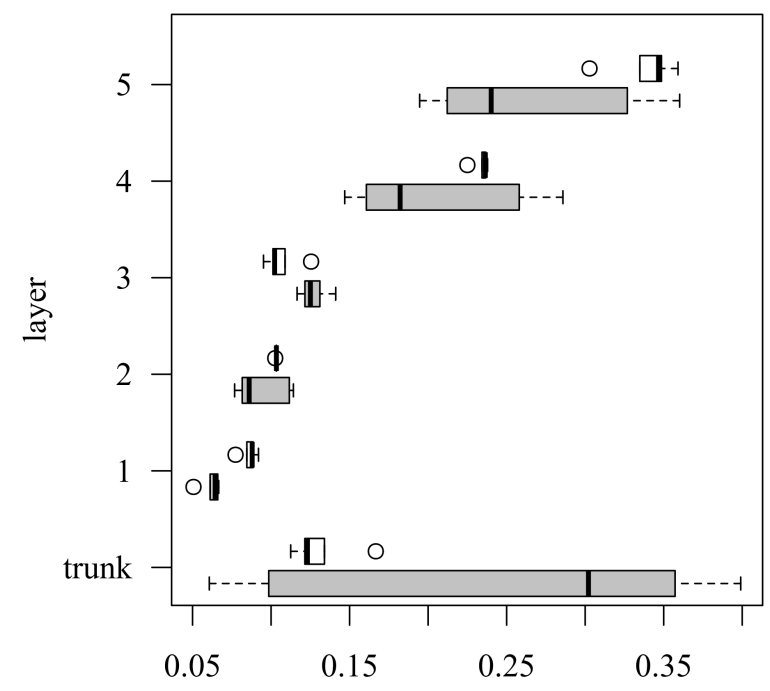

844

845 
bioRxiv preprint doi: https://doi.org/10.1101/2020.01.03.894303; this version posted January 3, 2020. The copyright holder for this preprint (which was not certified by peer review) is the author/funder. All rights reserved. No reuse allowed without permission.

$846 \quad$ Figure 6

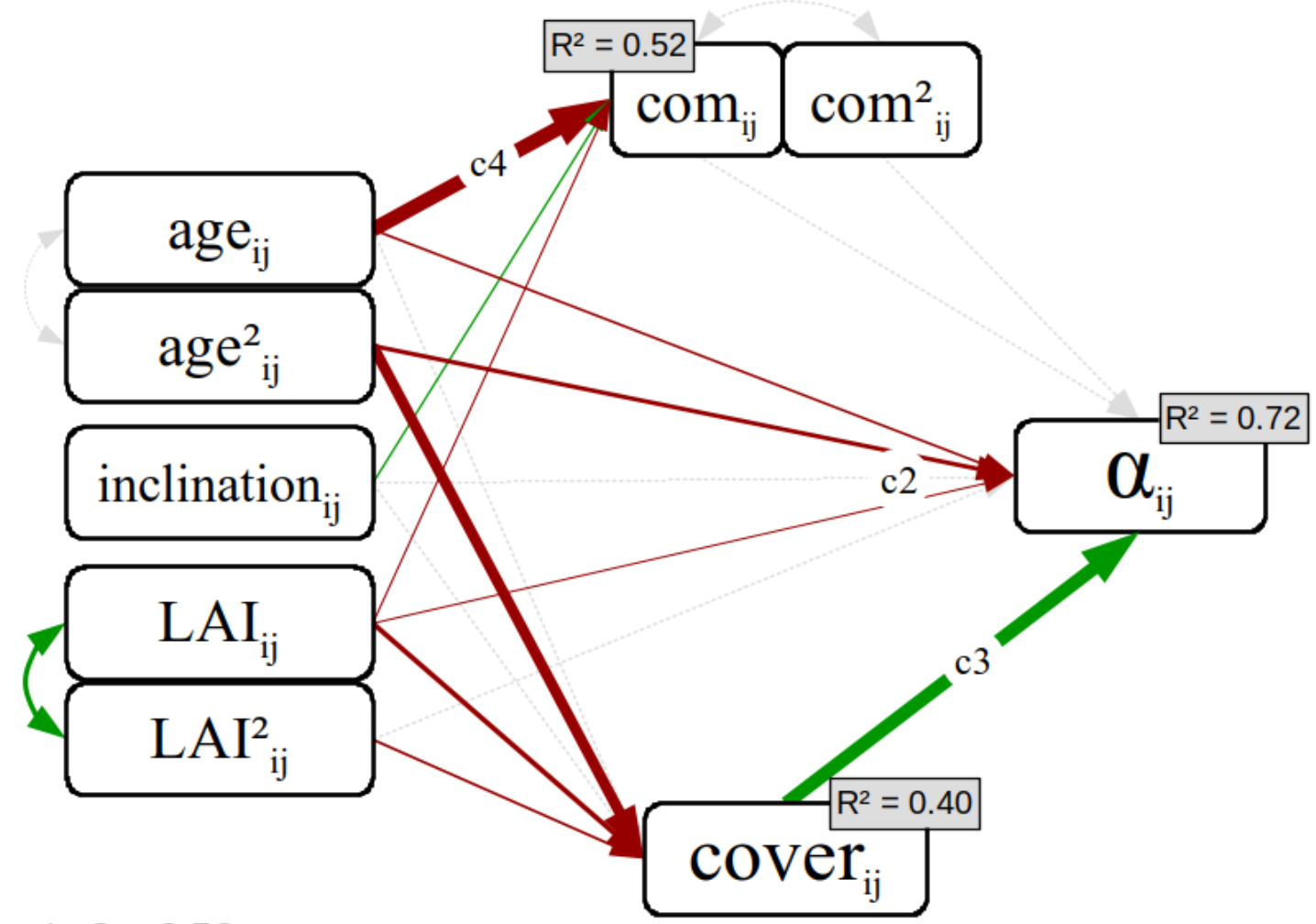

Fisher's $\mathrm{C}=8.52$

$(p=0.384)$ 


\section{$849 \quad$ Figure 7}

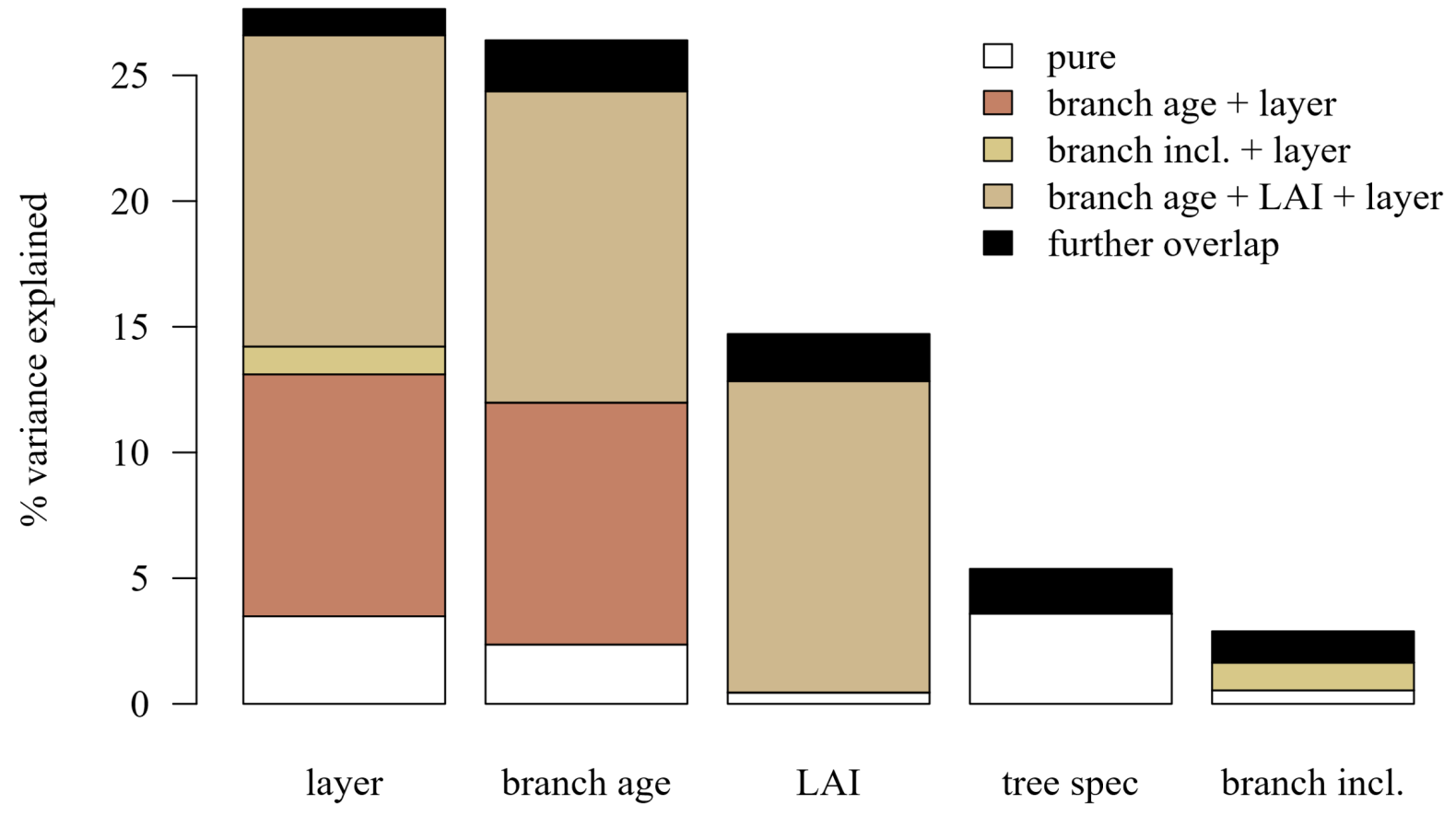




\section{Figure 8}

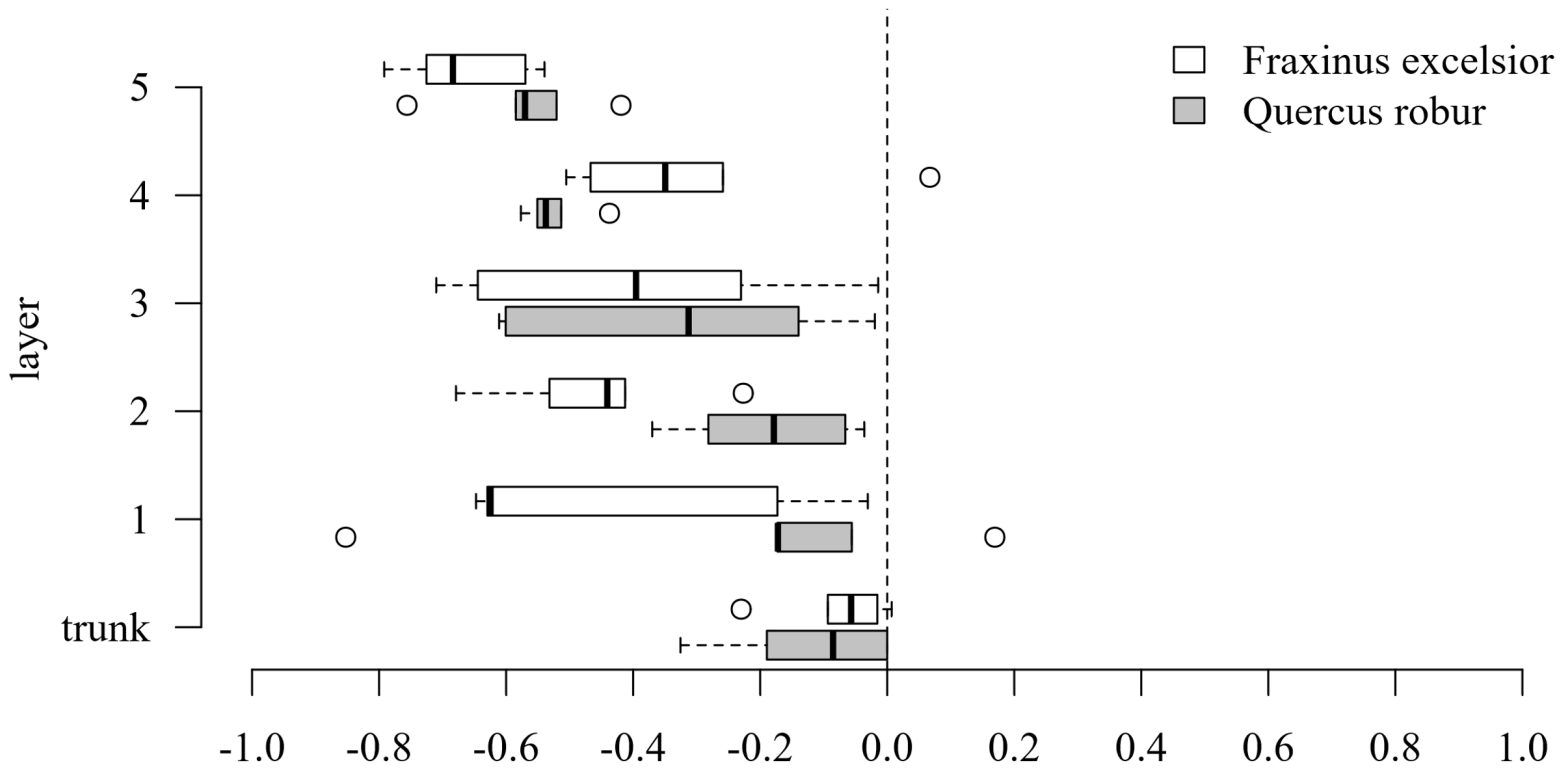


bioRxiv preprint doi: https://doi.org/10.1101/2020.01.03.894303; this version posted January 3, 2020. The copyright holder for this preprint (which was not certified by peer review) is the author/funder. All rights reserved. No reuse allowed without permission.

\section{$854 \quad$ Figure 9}

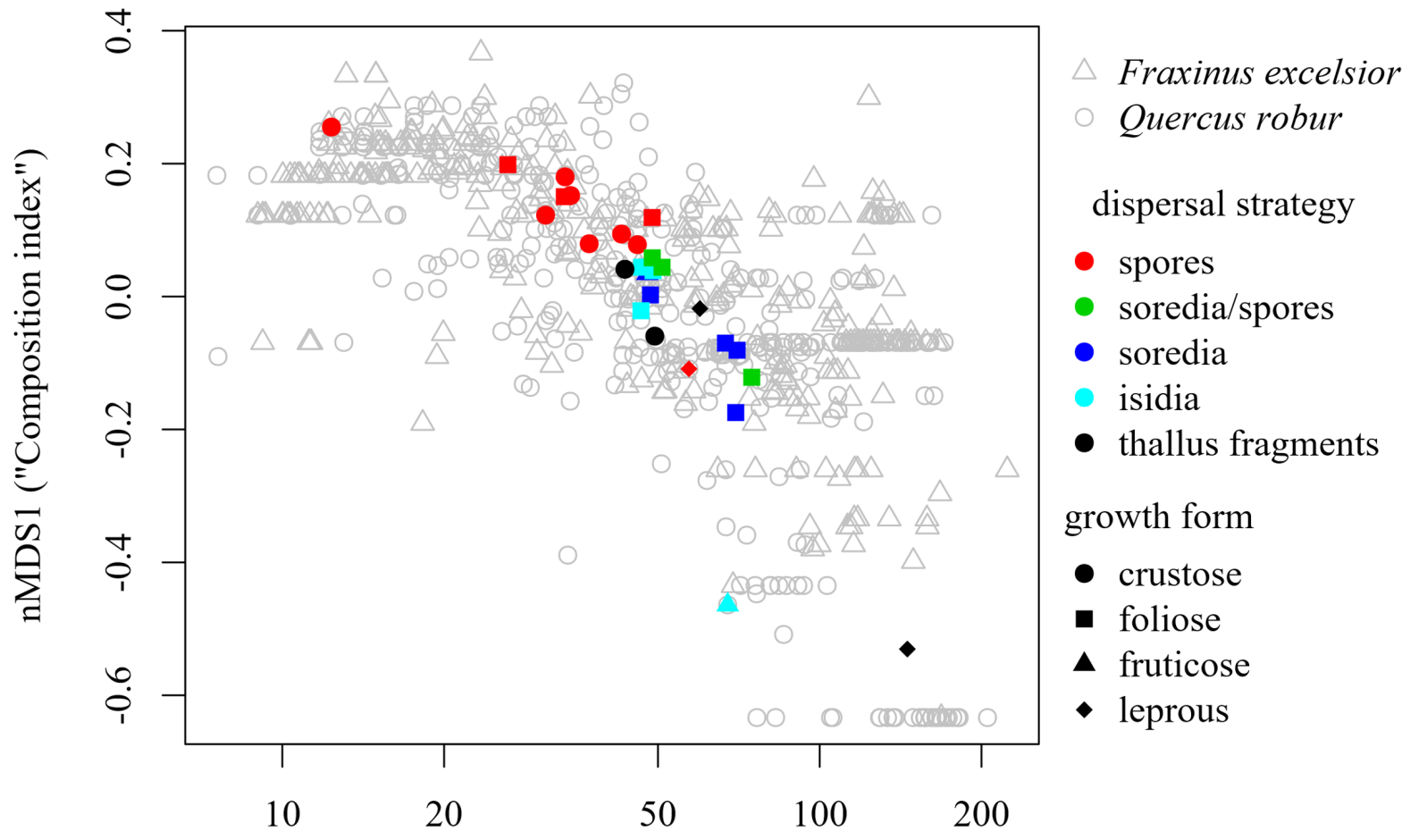

branch age

855

856 
bioRxiv preprint doi: https://doi.org/10.1101/2020.01.03.894303; this version posted January 3, 2020. The copyright holder for this preprint (which was not certified by peer review) is the author/funder. All rights reserved. No reuse allowed without permission.

\section{Figure 10a}

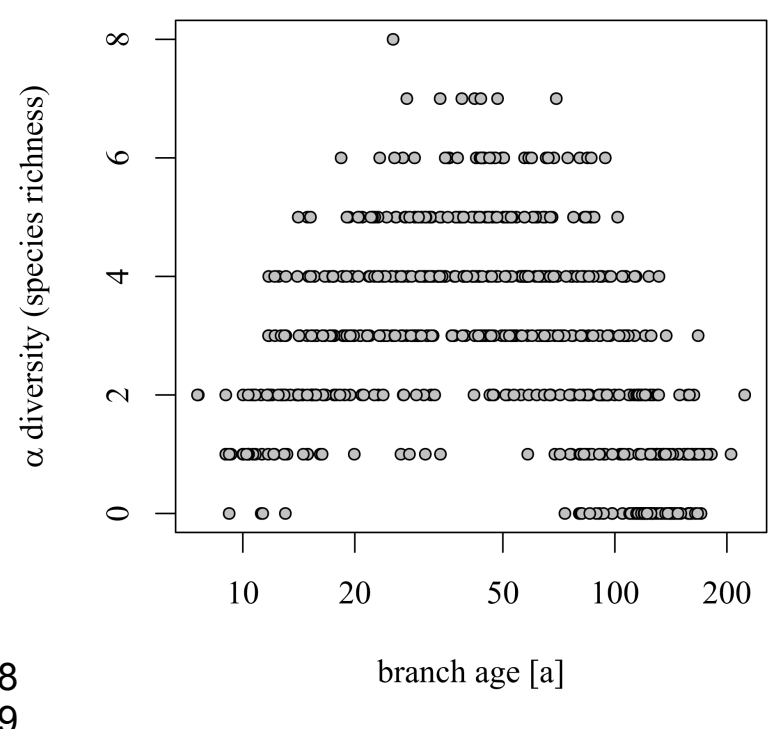

859 
bioRxiv preprint doi: https://doi.org/10.1101/2020.01.03.894303; this version posted January 3, 2020. The copyright holder for this preprint (which was not certified by peer review) is the author/funder. All rights reserved. No reuse allowed without permission.

\section{Figure $10 \mathrm{~b}$}

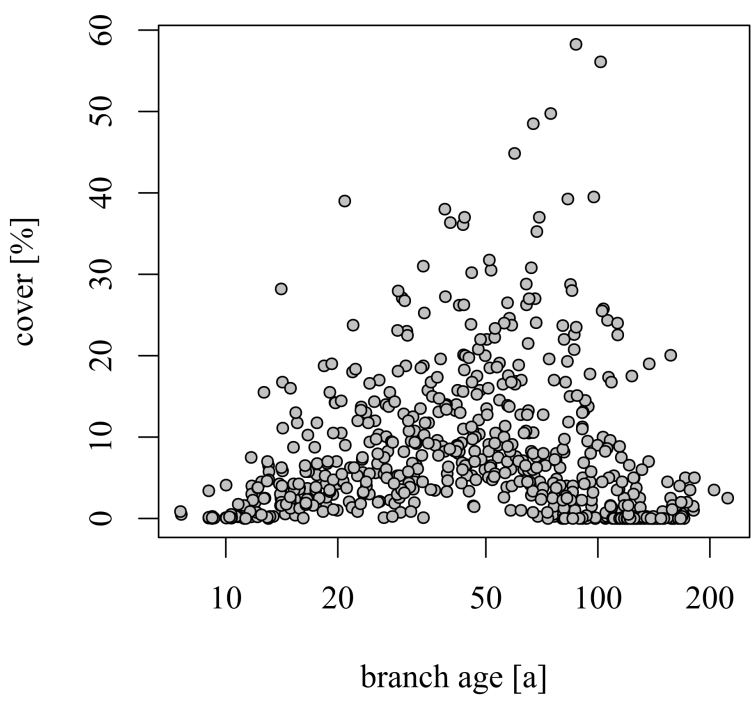

862 